\title{
Prolonged Enhancement of Anterior Thalamic Synaptic Responsiveness by Stimulation of a Brain-Stem Cholinergic Group
}

\author{
D. Paré, M. Steriade, M. Deschênes, and D. Bouhassira \\ Laboratoire de Neurophysiologie, Faculté de Médecine, Université Laval, Québec, Canada G1K 7P4
}

This study describes the effects of brain-stem cholinergic laterodorsal tegmental (LDT) stimulation on the synaptic responsiveness of anterior thalamic (AT) neurons. A sample of AT cells, physiologically identified by their short-latency (<6.5 msec) response to mammillary body (MB) stimulation, was recorded in unanesthetized, chronically implanted cats and in urethane-anesthetized cats.

In chronic experiments, LDT stimulation evoked a shortlatency (10-20 msec) excitation in most AT cells. Moreover, brief LDT trains ( 3 shocks at $300 \mathrm{~Hz}$, every $3 \mathrm{sec}$ ) enhanced the responsiveness of AT cells to both $M B$ (orthodromic) and cortical (ortho- and antidromic) stimuli. This effect did not vary as a function of the interval between LDT conditioning and MB or cortical testing shocks, but as a function of the number of trials. The effects of LDT stimuli resisted reserpine treatment $(0.75 \mathrm{mg} / \mathrm{kg})$, suggesting that they were not dependent on the coactivation of monoaminergic fibers. Finally, LDT trains did not suppress inhibitory processes in AT neurons when conditioning-testing intervals were longer than 60 msec.

Intracellular recordings performed in urethane-anesthetized cats revealed that LDT stimulation induced a shortlatency depolarization which increased with membrane hyperpolarization and was associated with an increase in apparent membrane conductance. Usually, isolated LDT trains did not evoke lasting changes in membrane potential or conductance. However, when LDT trains were applied every $3 \mathrm{sec}$, they gradually decreased the apparent membrane conductance without altering the membrane potential. This conductance change had a time course similar to the LDT-induced potentiation of responsiveness observed in the chronic experiments. In some neurons, LDT conditioning trains also induced a marked increase in the probability of fast prepotentials being triggered by subthreshold MB or cortical orthodromic volleys.

In order to distinguish the cumulative effects of repeated LDT trains from the possibly slow time course of LDT influences, we studied the effects of a unique 1 sec LDT train (at $30 \mathrm{~Hz}$ ) on the synaptic responsiveness of AT cells re-

Received Mar. 8, 1989; revised May 4, 1989: accepted May 5, 1989.

This work was supported by the Medical Research Council of Canada. D.P. is an MRC fellow. We thank P. Giguere and D. Drolet for their skillful technical assistance.

Correspondence should be addressed to Prof. Dr. M. Steriade at the above address.

Copyright $\subset$ C 1990 Society for Neuroscience $0270-6474 / 90 / 010020-14 \$ 02.00 / 0$ corded extracellularly in reserpine-treated, urethane-anesthetized animals. Such LDT trains induced a 2.9-fold increase in synaptic responsiveness, reaching its peak 40-50 sec after the LDT train and lasting up to $4 \mathrm{~min}$. lontophoretic application of the muscarinic blocker scopolamine blocked these long-lasting potentiating effects of LDT stimuli. Removal of cortical and basal forebrain inputs to the AT nuclear complex by appropriate transections did not abolish the potentiating effects of LDT trains.

We conclude that brain-stem cholinergic afferents increase the ability of thalamic cells to relay incoming signals toward the cortex for prolonged periods of time without disrupting the local inhibitory processes required for analytical processing.

The thalamus is not a passive relay station interposed between subcortical structures and the cortical mantle, but a dynamic synaptic network subserving 2 important functions. First, it increases the spatial and temporal resolution of the incoming messages by submitting relay cells to the inhibitory influence of local-circuit neurons and cells of the reticular (RE) thalamic nucleus. Second, it is a gating point where the information flow directed toward the cortex is controlled in a state-dependent manner (for a recent review, see Steriade and Llinás, 1988).

Early observations indicating that stimulation of the midbrain reticular formation (MRF) mimics the excitability changes occurring during transitions from slow-wave sleep (S) to the waking (W) state have led to the proposal that a brain-stem neuronal group is responsible for these state-dependent modulations of thalamic operations. Recent studies combining immunohistochemical and retrograde tracing methods have disclosed that 3 brain-stem cell groups have widespread projections to the thalamus: the raphe nuclei, the locus coeruleus complex, and 2 cholinergic groups located at the mesopontine junction: the peribrachial (PB) area and the laterodorsal tegmental (LDT) nucleus (Woolf and Butcher, 1986; Dolabela de Lima and Singer, 1987; Hallenger et al., 1987; Paré et al., 1988; Smith et al., 1988; Steriade et al., 1988). Various experimental results indicate that the thalamopetal pathway arising in the brain-stem cholinergic groups is largely responsible for the effects of MRF stimulation. First, the aforementioned morphological studies point out that the cholinergic contingent is, by far, the most important. Second, iontophoretic application of acetylcholine (ACh), like MRF stimulation, excites relay neurons in dorsal thalamic nuclei of cat (McCormick and Prince, 1987). Third, there is a striking correspondence between the location of thalamically projecting cholincrgic cells and the most cffective stimulation site to influence thalamic operations (Wilson et al., 1973). Finally, the 
effects of MRF stimulation can be blocked by iontophoretic applications of cholinergic antagonists (Phillis et al., 1967; Marshall and McLennan, 1972; Kayama et al., 1986; Francesconi et al., 1988; Hu et al., 1989a, b).

However, the time course and synaptic mechanisms of MRFevoked effects remain controversial. For instance, values ranging from $0.1 \mathrm{sec}$ (Singer, 1973) to $1 \mathrm{sec}$ (Doty et al., 1973) were reported for the duration of MRF facilitatory influences. As to the synaptic mechanisms involved, 2 contradictory hypotheses have been proposed. Sillito and collaborators (1983), as well as Eysel and coworkers (1986), have suggested that ACh directly excites both relay cells and Golgi type II local-circuit cells in the lateral geniculate (LG) nucleus. On the other hand, Singer and colleagues (Singer, 1973; Francesconi et al., 1988) maintain that direct excitatory influences of MRF afferents on LG relay cells are negligible. Instead, the facilitation of synaptic transmission induced by MRF stimulation would result from the inhibition of RE cells and local interneurons, leading to the disinhibition of relay cells. In agreement with this view, in vivo and in vitro studies have reported that MRF stimulation and/ or ACh application inhibit RE cells (Dingledine and Kelly, 1977; McCormick and Prince, 1986; Hu et al., 1989a) as well as local interneurons (McCormick and Pape, 1988) or the inhibitory processes mediated by them (Ahlsén et al., 1984; Francesconi et al., 1988). However, other experiments pointed out that MRF stimulation blocks the rhythmic long-lasting inhibitory periods but does not suppress the early inhibitory phase induced by ortho- or antidromic volleys (Steriade et al., 1977; Hu et al., 1989b). Moreover, lateral posterior (LP; Steriade et al., 1977), central lateral (CL; Steriade and Glenn, 1982) and LG (Hu et al., 1989b) thalamic cells are driven by MRF stimulation at latencies compatible with monosynaptic excitation. The existence of direct brain-stem-thalamic cholinergic excitations is supported by the effects of iontophoretically applied ACh after blockade of synaptic transmission in vitro. In this condition, ACh evoked direct depolarizations in a large proportion of cat LG cells (McCormick and Prince, 1987).

The reported absence of direct brain-stem-thalamic excitations probably arose from the fact that some of the aforementioned experiments were conducted in barbiturate-anesthetized animals, a condition depressing the sensitivity of thalamic neurons to ACh applications and MRF stimulation (Ogawa, 1963; Eysel et al., 1986; Pape and Eysel, 1988; Hu et al., 1989b). Moreover, some characteristics of the thalamic synaptic network greatly complicate the interpretation of MRF influences on relay cells. For instance, GABAcrgic RE cclls contact both relay neurons and local-circuit inhibitory cells (cf. Montero, 1987) with unknown consequences for relay neurons.

To circumvent these problems, we have investigated the effects of high-frequency brain-stem stimulation on the neurons of a nuclear group characterized by a simpler synaptic network, the anterior thalamic (AT) nuclei. Although their ultrastructural organization is similar to that found in other thalamic nuclei (Somogyi et al., 1978), AT nuclei are devoid of afferents from the RE thalamic nucleus (Steriade et al., 1984; Velayos et al., 1989). Yet, AT cells are endowed with the basic electrophysiological properties (Mulle et al., 1985; Paré et al., 1987) that characterize most dorsal thalamic neurons (Jahnsen and Llinás, 1984a, b). Moreover, they receive an important contingent of cholinergic fibers (Levey et al., 1987) arising mainly in the LDT nucleus of both rat (Hallenger et al., 1987) and cat (Steriade et al., 1988) and contain high densities of both nicotinic and mus- carinic receptors (Clarke et al., 1985; Friedman et al., 1985; Mash and Potter, 1986).

Our study comprises 2 parts: the first one investigates the effects of LDT stimulation on AT cells recorded extracellularly in unanesthetized, chronically implanted cats. It was found that LDT stimulation excites most AT cells at short latencies and increases their responsiveness to both ortho- and antidromic stimuli. The second part is an intra- and extracellular study of the mechanisms underlying the long-lasting potentiating effects of LDT stimulation on the synaptic responsiveness of AT cells performed in urethane-anesthetized cats.

\section{Materials and Methods}

\section{Chronic experiments}

Preparation. These experiments were conducted on 8 chronically implanted cats weighing between 2.5 and $3.5 \mathrm{~kg}$. Surgery was performed under deep barbiturate anesthesia (sodium pentobarbital, $35 \mathrm{mg} / \mathrm{kg}$ ). Stainless steel screws were anchored to the calvarium overlying the suprasylvian gyrus to record electroencephalographic (EEG) rhythms. Two Teflon-insulated wires were inserted in the neck muscles to pick up electromyographic (EMG) activity and 2 silver-ball electrodes were cemented into the supraorbital cavity to record eye movements (EOG).

Stimulating electrodes consisted of 2 pairs of concentric electrodes (1.5 mm apart, with tips bared at $0.1-0.3 \mathrm{~mm}$ ), one in the mammillary body (MB) and one in the LDT. In addition, an array of 3 electrodes (cemented $1.5 \mathrm{~mm}$ apart from each other) was inserted in the posterior cingulate cortex. The calvarium overlying AT nuclei was removed, and the exposed dura was covered with a polystyrene cylinder. Cats were implanted in a stereotaxic position with 4 screws protruding out of the dental cement. These screws were later used for rigidly fixing the cat's head to the stereotaxic apparatus without pain or pressure. Bicillin was given postoperatively for $3 \mathrm{~d}$. Recordings began 6-9 d after surgery. Animals slept ad libitum between experimental sessions.

Recording. Isolated neurons (with a signal-to-noise ratio $>5: 1$ ) were recorded with tungsten microelectrodes $(2-6 \mathrm{M} \Omega$ at $1 \mathrm{kHz}$ ). Unit recordings and focal waves were recorded simultaneously on direct (50$10,000 \mathrm{~Hz})$ and FM (1-700 Hz) channels of a tape recorder. Physiological variables used to identify behavioral states such as EEG, EOG, and EMG signals were also recorded. For a detailed account of the electrographic criteria used to distinguish behavioral states of vigilance, see Steriade and Hobson (1976).

Neuronal identification. Since the cortical projection fields of AT nuclei overlap extensively with those of other thalamic nuclei, such as the reuniens (Herkenham, 1978), lateralis dorsalis (Robertson and Kaitz, 1981), and CL (Kaufman and Rosenquist, 1985), monosynaptic activation at short latency by $\mathrm{MB}$ stimulation was considered the only reliable criterion to identify AT neurons unequivocally. This paper will only describe physiologically identified AT neurons.

AT neurons were formally identified as thalamocortical cells when they could also be antidromically invaded from the cingular cortex. The criteria used for antidromic identification were fixed-response latency, collision with spontaneously occurring action potentials, and ability to follow high-frequency stimulation $(>250 \mathrm{~Hz}$ ). Presumed fibers, with exclusively positive action potentials lasting less than $0.8 \mathrm{msec}$, were not considered.

Stimulation parameters and experimental paradigm. The stimulation parameters used for MB, cingular cortex, and LDT shocks $(0.05-0.2$ msec pulses of $0.01-0.2 \mathrm{~mA}$ at $0.3 \mathrm{~Hz}$ ) did not elicit eye movements, nor did they interfere with the normal sleep-waking cycle.

When studying anti- or orthodromic responsiveness, stimulation intensity was usually adjusted to elicit discharges in approximately 30 $70 \%$ of the trials to avoid saturation effects. To rule out the possibility of order effects when studying stimulus-induced inhibitory periods (see below) or LDT influences on AT responsiveness, the presentation order of the intervals between the various stimuli was systematically varied. To verify if the effects of LDT stimulation resulted from the coactivation of monoaminergic passing fibers, the same tests were performed 24-48 $\mathrm{hr}$ after reserpine treatment (Serpasil, $0.75 \mathrm{mg} / \mathrm{kg}$ ) in a sample of identified AT cells.

Electrolytic lesions $(0.3 \mathrm{~mA}$ for $10 \mathrm{sec})$ were made along successful microelectrode tracks for subsequent histological controls. At the end of the experiment, cats were deeply anesthetized (sodium pentobarbital, 
$50 \mathrm{mg} / \mathrm{kg}$ ) and perfused with 0.5 liter of $0.9 \%$ saline followed by 1 liter of $4 \%$ paraformaldehyde. The positions of the stimulating and recording electrodes were later verified on $80 \mu \mathrm{m}$ thionin-stained frontal sections. By combining histological controls and micrometer readings, it was possible to locate the position of the cells recorded within the limits of the AT complex.

Data analysis. Analyses were performed off-line on an IBM 3031 computer. To evaluate antidromic and synaptic responsiveness, poststimulus histograms (PSH) were performed. Grouped PSH were also calculated. Nonparametric tests such as the Mann-Whitney $U(U)$ and the Wilcoxon (WX) tests were used.

\section{Acute experiments}

Preparation. These experiments were performed on 41 adult cats anesthetized with urethane $(1.8 \mathrm{gm} / \mathrm{kg})$. This anesthetic was chosen because previous experiments carried out in this laboratory (Hu et al., 1989a b) have revealed that urethane administration does not affect thalamic responses to MRF stimulation. The animals were paralyzed with gallamine triethiodide (Flaxedil, i.v.) and artificially ventilated. The endtidal concentration in $\mathrm{CO}_{2}$ was kept at $3.7 \pm 0.2 \%$ and the body temperature maintained at $38^{\circ} \mathrm{C}$. Stimulating electrodes were inserted in the $\mathrm{MB}$ and presubicular cortex to activate $\mathrm{AT}$ cells. A concentric stimulating electrode was also placed in the LDT nucleus. To insure that the effects of LDT stimulation did not reflect the coactivation of monoaminergic fibers, reserpine (Serpasil, $0.75 \mathrm{mg} / \mathrm{kg}$ ), a monoamine depletor, was administered $18-20 \mathrm{hr}$ before the experiments. Previous studies have shown that reserpine can reduce the brain content in serotonin and catecholamine by $80-95 \%$ (Carlsson, 1966). Details concerning the parameters of stimulation, criteria used for the physiological identification of AT cells, as well as the procedures utilized for histological controls, are mentioned above.

Intracellular recordings. Twenty-seven cats were used for these experiments. Stability of recordings was insured by cisternal drainage and bilateral pneumothorax. The cortex overlying the thalamus was removed by suction and intracellular recordings were performed with micropipettes filled with a $3.5 \mathrm{M}$ solution of potassium acetate (tip diameter, $0.5 \mu \mathrm{m}$; DC resistance, 25-35 M $\Omega$ ). A high-impedance amplifier with active bridge circuitry (Neurodata, model IR-283) was used to record and inject current inside the cells. Data were recorded on a 4-channel tape recorder with FM electronics (bandwidth, 0-5 kHz).

Extracellular recordings. These experiments were conducted on 14 cats. MB and cortical shocks were given at $1 \mathrm{~Hz}$ and the intensity of stimulation was adjusted to elicit ortho- and/or antidromic responses in approximately $20 \%$ of the trials. LDT stimuli consisted in a unique $0.5-1.5 \mathrm{sec}$ train of $0.1 \mathrm{msec}$ pulses $(0.1 \mathrm{~mA})$ at $30 \mathrm{~Hz}$.

In 3 cats, the effect of iontophoretically applied scopolamine on LDTinduced changes in AT responsiveness was studied. Pipette assemblies were constructed in the following way. A 2-barrel pipette (tip at 5-7 $\mu \mathrm{m}$ ) was glued to a single-barrel pipette (tip at $0.8-1.2 \mu \mathrm{m}$ ) so that the tip of the latter protruded $15-20 \mu \mathrm{m}$ beyond that of the 2-barrel pipette. The single-barrel pipette was filled with $3.5 \mathrm{M}$ potassium acetate $(5-10$ $\mathrm{M} \Omega$ ) and served as a recording electrode. One barrel of the 2-barrel pipette was filled with $\mathrm{NaCl}(0.6 \mathrm{M})$ for current compensation, while the other contained scopolamine $\mathrm{HCl}$ (Sigma, 0.1 M, pH 4.2). A retaining current of $10 \mathrm{nA}$ was passed through the scopolamine-filled barrel. Ejection currents of 10-30 nA were used.

Finally, to rule out the possibility that LDT effects on AT cells were the consequence of polysynaptic effects involving the cortex and/or basal forebrain (Steriade et al., 1987; Parent et al., 1988), 4 of the cats were prepared in the following way. First, the cingular cortex and fornix overlying the AT complex was removed by suction. Then, frontal (A13) and parasagittal (L4) sections were made to interrupt basal forebrain and cortical fibers, respectively.

\section{Results}

\section{Data base}

Chronic experiments. A total of 301 neurons were recorded within the limits of the AT complex. Of these, 92 were monosynaptically activated by $\mathrm{MB}$ stimulation at latencies shorter than $6.5 \mathrm{msec}(3.88 \pm 0.79$, mean $\pm \mathrm{SD})$. In keeping with the large cortical projection field of the AT nuclear group and the small number of cortical stimulating electrodes used in this study, only $9 \%$ of $\mathrm{MB}$ driven cells were backfired from the cingular cortex. Thirteen identified AT cells were recorded after reserpine treatment.

Acute experiments in urethane-anesthetized cats. A total of $60 \mathrm{AT}$ neurons having a resting potential $\geq 50 \mathrm{mV}$ were recorded intracellularly in 27 cats. In addition, 51 AT neurons were recorded extracellularly in 14 reserpine-treated cats. Of these 51 cells, 19 neurons were recorded after interruption of cortical and basal forebrain inputs. In 10 cells, the effect of iontophoretically applied scopolamine on LDT-induced changes in AT responsiveness was tested.

\section{Extracellular recordings in unanesthetized behaving cats}

LDT-evoked discharges. In $78 \%$ of the AT cells tested $(n-37)$, LDT stimulation ( 3 shocks at $300 \mathrm{~Hz}$, every $3 \mathrm{sec}$, unless otherwise stated) elicited 1-3 spikes at a latency of $12-20 \mathrm{msec}$ (Fig. 1, $A, B$ ). This primary excitation was followed in $11 \%$ of the cells by a subtle but prolonged period of increased discharge rate beginning $600-800 \mathrm{msec}$ after LDT shocks and lasting around $2 \mathrm{sec}$ (not illustrated). In the remaining $22 \%$ of neurons, the initial excitation appeared later ( $40-80 \mathrm{msec})$. No consistent differences were found between LDT-evoked responses in waking (W), EEG-synchronized (S), and EEG-desynchronized sleep (D).

In order to verify if these effects were dependent upon the coactivation of monoaminergic fibers, the same tests were carried out after reserpine treatment. In reserpine-treated animals, the initial response persisted in the $8 \mathrm{AT}$ neurons tested (Fig. 1C). The late excitatory response was never observed after reserpine treatment.

Effects of LDT stimulation on AT cellular responsiveness. The effect of LDT stimulation on the responsiveness of 27 AT cells was studied in electrographically steady periods of $W$ and $S$. Because of the marked nonstationarity of D epochs (Paré et al., 1989), these tests were not carried out in D. LDT stimulation increased the orthodromic responsiveness of AT cells to MB (17 cells out of 19) and cingular cortex stimulation (4 cells out of 4), as well as the probability of antidromic invasion following cingular cortex stimulation (3 out of 4 ). An example of LDTinduced potentiation of synaptic responsiveness is illustrated in Figure 2. In this particular case, LDT stimulation induced a 3 -fold increase in the responsiveness of the cell under study. The enhancing effects of LDT conditioning trains could be elicited in $W$ as well as in $S$. In all neurons tested $(n=6)$, the enhancing effects of LDT shocks resisted reserpine treatment. Statistical analyses confirmed the significance of LDT-induced effects (WX, $p<0.05$ ).

The effect of LDT trains on the synaptic responsiveness of 16 AT cells was studied with different intervals between conditioning and testing shocks. Unless the conditioning-testing interval was so short that the response to the testing shock occurred during the primary excitation elicited by LDT shocks, it was found that LDT effects did not vary as a function of the interval between LDT and testing shocks but as a function of the number of trials. Figure 3 illustrates this point. Throughout the experiment, MB shocks were given every $3 \mathrm{sec}$, and the number of short-latency responses was computed every 10 shocks (ordinate in Fig. $3 A 6$ ). From time -2 min to time 0 , only MB stimuli were given. However, from time 0 to time $4 \mathrm{~min}$, each MB shock was preceded by a short LDT train (conditioningtesting interval $200 \mathrm{msec}$ ). From a control value of $1 / 10$, the number of responses gradually increased until a plateau of 5- 

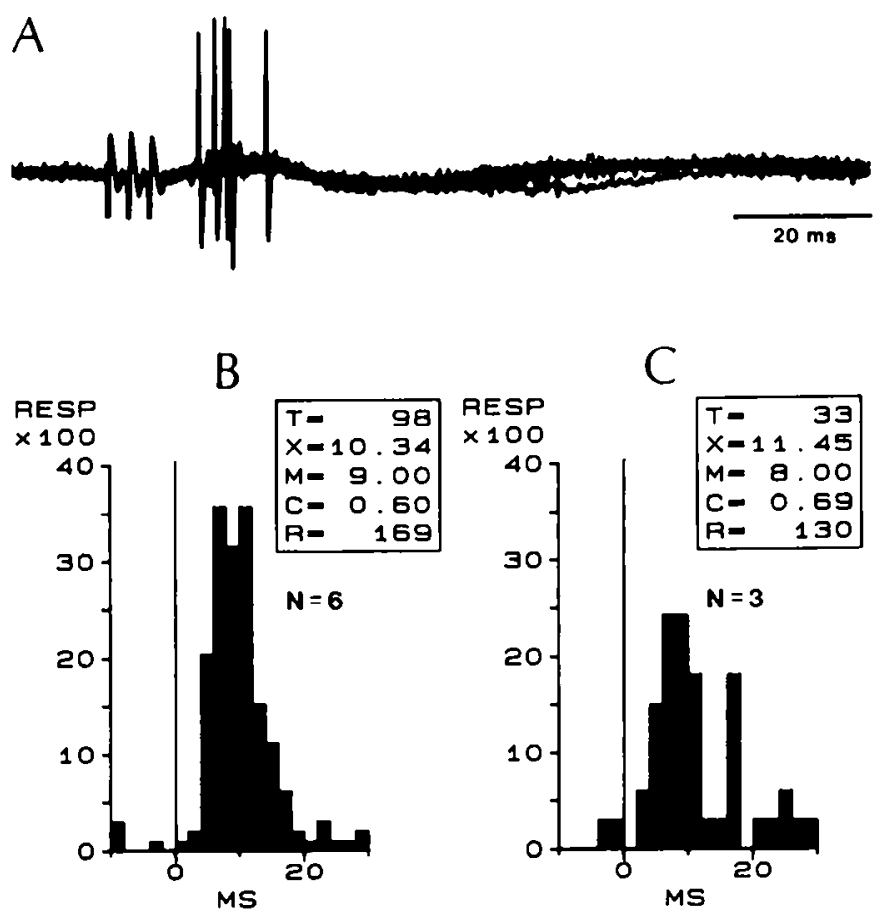

Figure 1. Short-latency orthodromic activation of AT neurons by LDT stimulation. Unanesthetized, chronically implanted cats. $A$, Response of an AT neuron to LDT stimulation. Five superimposed sweeps. LDT stimuli consisted of 3 shocks at $300 \mathrm{~Hz}$. Grouped peristimulus histograms depicting the response of AT cells to LDT stimulation recorded in $S(B, n=6)$ and $24-48 \mathrm{hr}$ after reserpine treatment $(C, n=3)$. Note the persistence of the response after reserpine treatment. $T$, number of trials; $X$, mean latency; $M$, latency mode; $C$, coefficient of variation; $R$, responsiveness defined as the total counts in the depicted range divided by the number of trials and expressed as a percentage.

6/10 was reached, 2 min after the onset of LDT shocks. When LDT shocks were interrupted (time $4 \mathrm{~min}$ ), the response probability remained elevated for $1 \mathrm{~min}$ and gradually returned to baseline values. Figure $3 B$ illustrates the mean responsiveness of 6 different cells in such experiments. Although the effects of LDT shocks were not generally as dramatic as in Figure $3 A$, a mean increase of 2.1 times in the number of short-latency responses to MB stimulation was calculated. The problems raised by the natural shifts in states of vigilance and associated changes in cellular excitability (Paré et al., 1989) were circumvented by testing the effects of LDT stimuli in anesthetized cats (see below).

LDT influences on AT inhibitory processes. By comparing the response probability of $\mathrm{AT}$ cells to 2 consecutive $\mathrm{MB}$ shocks 10-150 msec apart, it was found that a period of decreased responsiveness consistently followed the orthodromic activation of AT cells. This reduction in responsiveness had a mean amplitude of $39 \%$, reached its peak $30-40 \mathrm{msec}$ after the first shock, and lasted for 70-80 msec. In order to study LDT influences on AT inhibitory processes, the effect of LDT conditioning shocks on the responsiveness of 5 AT cells to 2 consecutive MB shocks (40 msec apart) were studied (Fig. 4). Various intervals between conditioning and testing shocks were used. With intervals longer than $60 \mathrm{msec}$, LDT shocks increased the responsiveness of AT cells to both MB shocks without interfering with the inhibitory period induced by the first MB shock. However, when shorter conditioning-testing intervals $(20 \mathrm{msec})$ were used, the inhibitory period was no longer evident.

\section{Intracellular recordings in urethane-anesthetized cats}

Short-latency response of $A T$ cells to LDT stimulation. The effects of LDT stimulation were studied in 39 AT cells. In $64 \%$ of the cells, LDT stimulation (usually 2-3 shocks at $300 \mathrm{~Hz}$ ) evoked a short-latency $(7.42 \pm 0.66 \mathrm{msec})$ depolarization that could trigger action potentials (Fig. $5 A$ ). At resting potential, when stimulation intensity was adjusted just below the threshold for action potential generation, this depolarization had a duration of $24.75 \pm 8.02 \mathrm{msec}$ and a peak amplitude of $4.8 \pm$ $0.62 \mathrm{mV}$. The amplitude of this depolarization increased slightly with membrane hyperpolarization (Fig. 5, $A, C$ ) and was associated with a marked increase in the apparent membrane conductance (Fig. $5 B$ ) averaging $21 \%$ in the 11 tested cells (Fig. $5 B$ ). In $18 \%$ of the neurons, LDT-evoked depolarizations triggered fast-rising depolarizing events sensitive to hyperpolarizing currents (Fig. 5C). These depolarizing events had an amplitude of $4.1 \pm 0.9 \mathrm{mV}$ and were usually characterized by a fast-rising phase and a slower fall time (Fig. 5C4). Because these fastdepolarizing events were often seen to trigger full action potentials (see below and Figs. 8, 9), they are hereafter termed fast prepotentials (FPPs).

In $8 \%$ of the cells, LDT stimulation evoked a longer-latency $(33.67 \pm 12.65 \mathrm{msec})$ depolarization, usually beginning by a burst of FPPs superimposed on a slowly rising depolarization (Fig. 6). Altogether, this depolarization could last up to $1 \mathrm{sec}$. No consistent change in membrane conductance was observed during this long-lasting response.

In a few cells ( $5 \%$ of the sample), LDT-stimulation evoked a short-latency hyperpolarizing potential (not illustrated). However, this IPSP had a small amplitude and required high stimulation intensities to be elicited. It was not studied further. Twenty-three percent of the cells were unresponsive to LDT stimulation.

Long-term effects of LDT stimulation on membrane conductance and potentials of $A T$ neurons. In the large majority of AT cells $(92 \%)$, LDI stimulation had no lasting effects on their membrane potential. Similarly, when LDT trains were delivered slowly (every $20 \mathrm{sec}$ ), the apparent membrane conductance of the tested cells $(n=9)$ remained constant (Fig. 7A). However, in 5 out of 9 tested cells, higher stimulation rates (every $3 \mathrm{sec}$ ) induced a gradual decrease in apparent membrane conductance reaching up to $25 \%$ but averaging $18.2 \%$. As illustrated in Figure $7 B$, this reduction of the apparent membrane conductance developed slowly, reached its peak after more than $1 \mathrm{~min}$, and persisted for up to $30 \mathrm{sec}$ following the cessation of LDT shocks.

Influence of $L D T$ stimulation on $A T$ responsiveness. When studying the effects of LDT conditioning trains on intracellularly recorded AT neurons, subthreshold stimuli were applied to the $\mathrm{MB}$ or presubicular cortex. In most cases (18 out of 28 cells), close examination of $\mathrm{MB}$-evoked potentials revealed the presence of 2 distinct components: (1) an early EPSP which grew in amplitude with membrane hyperpolarization and (2) an all-ornone event which appeared on the rising phase of the EPSP and was abolished by membrane hyperpolarization. Figure 8 illustrates the effect of membrane hyperpolarization on MB-evoked responses. At resting potential $(A)$, FPPs usually triggered action potentials. In these cases, EPSPs, FPPs, and action potentials could still be distinguished by the steepness of their rising phase (see arrows in the inset of Fig. 8A). The injection of hyperpolarizing current abolished action potentials (Fig. $8 B$ ), gradually increased the amplitude of the EPSP (Fig. $8 C-F$ ), and finally 
Figure 2. Enhancement of AT synaptic responsiveness by LDT stimulation. $A$, AT neuron recorded during a stable period of S. In this case, 30 shocks were given to the MB; 15 without LDT shocks and 15 with conditioning LDT stimuli. Each trial was separated by 3 sec. Only 1 sweep out of 3 is shown here. LDT stimuli consisted of 3 shocks given at $300 \mathrm{~Hz}, 90 \mathrm{msec}$ before MB shocks. Note the early response to LDT stimulation and the increase in synaptic responsiveness to MB stimuli. $B$, PSHs showing the responsiveness of the same AT cell to MB stimuli before (I) and during (2) the period with LDT conditioning shocks. For symbols, see legend of Figure 1.

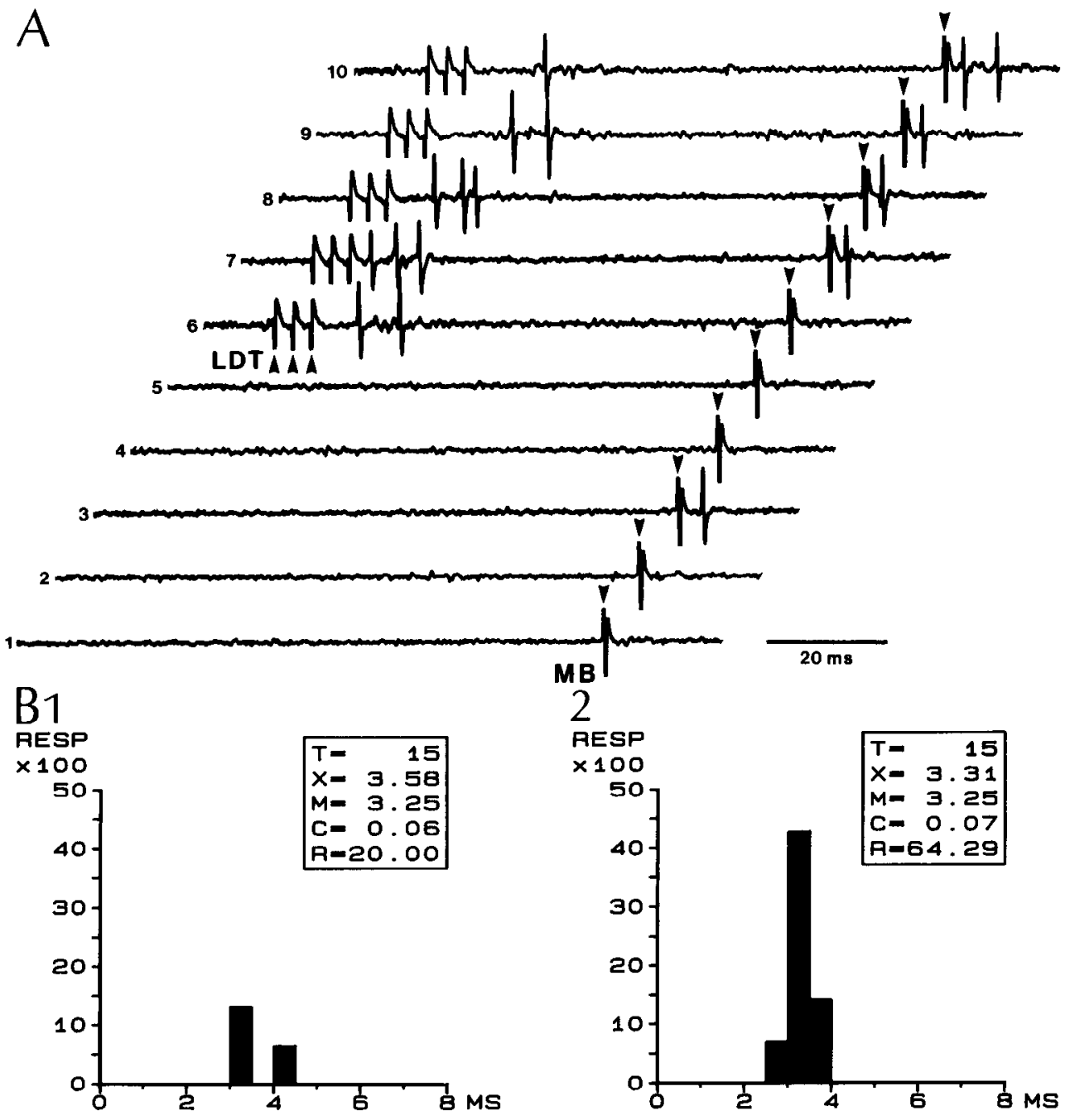

suppressed the FPPs (Fig. $8 F$ ). The time course and amplitude of the FPPs were modified by membrane hyperpolarization. First, its amplitude increased and its rise time decreased. Then, its slow repolarizing phase was replaced by a more rapid repolarization.

As expected, when the interval between LDT conditioning shocks and subthreshold MB or cortical stimuli was adjusted so that MB- or cortically evoked responses occurred during the LDT-induced depolarizations, the probability of orthodromic activation was dramatically enhanced (not illustrated). An unexpected phenomenon was observed when the interval between LDT trains and testing shocks was longer than $40 \mathrm{msec}$. In those cases, repetitive LDT trains gradually increased the responsiveness of AT cells to both cortical ( 10 out of 12 cells) and MB ( 7 out of 10 cells) shocks, without any change in membrane potential. Following cessation of LDT trains, the responsiveness of AT cells remained elevated for up to $30 \mathrm{sec}$ and gradually returned to baseline values.

When stimulation intensity was adjusted so that MB or cortical shocks evoked only an isolated EPSP, LDT conditioning trains gradually increased the probability of FPP occurrence in 3 and 6 AT cells, respectively. These FPPs eventually triggered full spikes. Figure 9 illustrates such an experiment. In the control situation, MB shocks evoked only an EPSP. After 30 LDT trains, most MB shocks evoked an FPP which occasionally triggered action potentials. One minute after the interruption of LDT trains, the cell's responsiveness was almost back to control levels. In agreement with the hypothesis suggesting that FPPs are dendritic spikes serving as a boosting mechanism for remote synaptic inputs (Llinás and Nicholson, 1971), it was observed that LDT trains can increase the probability of cortically triggered FPP without any detectable underlying EPSP (Fig. 10).

Taken together, these results suggest that LDT stimulation enhances the synaptic responsiveness of AT cells by closure of ionic channels. The resulting increased input resistance would allow synaptic events of small amplitude to depolarize parts of the dendritic membrane sufficiently to trigger FPPs and, eventually, somatic action potentials.

\section{Extracellular recordings in acute experiments: long-lasting enhancement of responsiveness}

When using repetitive trains to study LDT influences on AT responsiveness, it is difficult to distinguish the additive effects of successive LDT trains from the slow time course of LDT influences. Moreover, short high-frequency trains are highly unnatural stimuli since most thalamically projecting PB and LDT neurons discharge tonically at $20-40 \mathrm{~Hz}$ in unanesthetized behaving animals (our current experiments). 

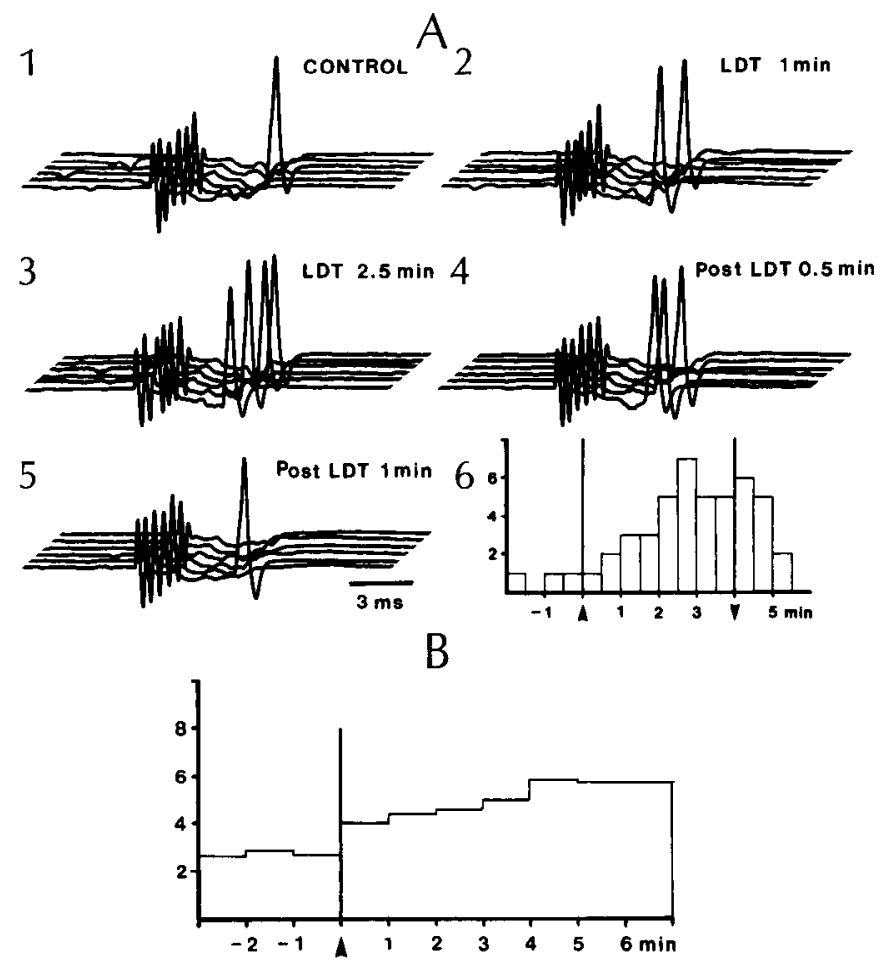

Figure 3. Slow time course of LDT-induced enhancement of AT synaptic responsiveness. $A$, Juxtacellularly recorded AT neuron during a long and uninterrupted period of S. 1-5, Groups of 6 consecutive oscilloscopic traces showing test shocks applied to the MB. Only one MB shock was given per trial. In this experiment, MB shocks were given every $3 \mathrm{sec}$, first without conditioning LDT shocks $(I)$, then with LDT shocks $(2,3)$ and finally without LDT shocks $(4,5)$. The conditioningtesting interval was equal to $200 \mathrm{msec}$. Temporal coordinates are given for each group of oscilloscopic traces. These indications can be related to the histogram (6) showing how the responsiveness of this AT neuron fluctuated during the experiment. Ordinate, number of short-latency responses out of 10 trials (or $30 \mathrm{sec}$ ). $B$, Grouped histogram showing the effect of LDT conditioning shocks on the responsiveness of $6 \mathrm{AT}$ neurons to MB shocks during S. Ordinate and abscissa as in $A 6$. Note the slow and additive effects of LDT shocks.

Thus, in order to gain a better understanding of the mechanisms underlying LDT effects, a different approach was used. Instead of repeated high-frequency LDT trains, a single $0.5-1.5$ sec pulse-train (at $30 \mathrm{~Hz}$ ) was given, and its effect on the responsiveness of extracellularly recorded AT cells to $10 \mathrm{MB}$ or presubicular shocks (at $1 \mathrm{~Hz}$ ) was assessed every $10 \mathrm{sec}$. Figure 11 illustrates such an experiment. The stimulation intensity was adjusted to elicit short-latency spikes 1-3 times out of 10 trials. In this neuron, the LDT train induced a 5-fold increase in synaptic responsiveness which developed slowly, reaching its peak after $40-60 \mathrm{sec}$. It lasted $80 \mathrm{sec}$ when induced by a $0.5 \mathrm{sec}$ LDT train (Fig. $11 \mathrm{Al}$ ) and as much as 3 min when a $1 \mathrm{sec}$ LDT train was applied (Fig. 11A2). In 10 out of the 14 tested cells, a similar responsiveness potentiation was obtained with presubicular testing shocks (Fig. 11B).

Figures 12 and 13 illustrate other examples of LDT-induced enhancement of synaptic and antidromic responsiveness, respectively. In Figure 13, note that the LDT train increased the number of initial segment (IS) and somatodendritic spikes (SD) evoked by the cortical shocks.

In 16 cells, a strictly standardized procedure was applied to
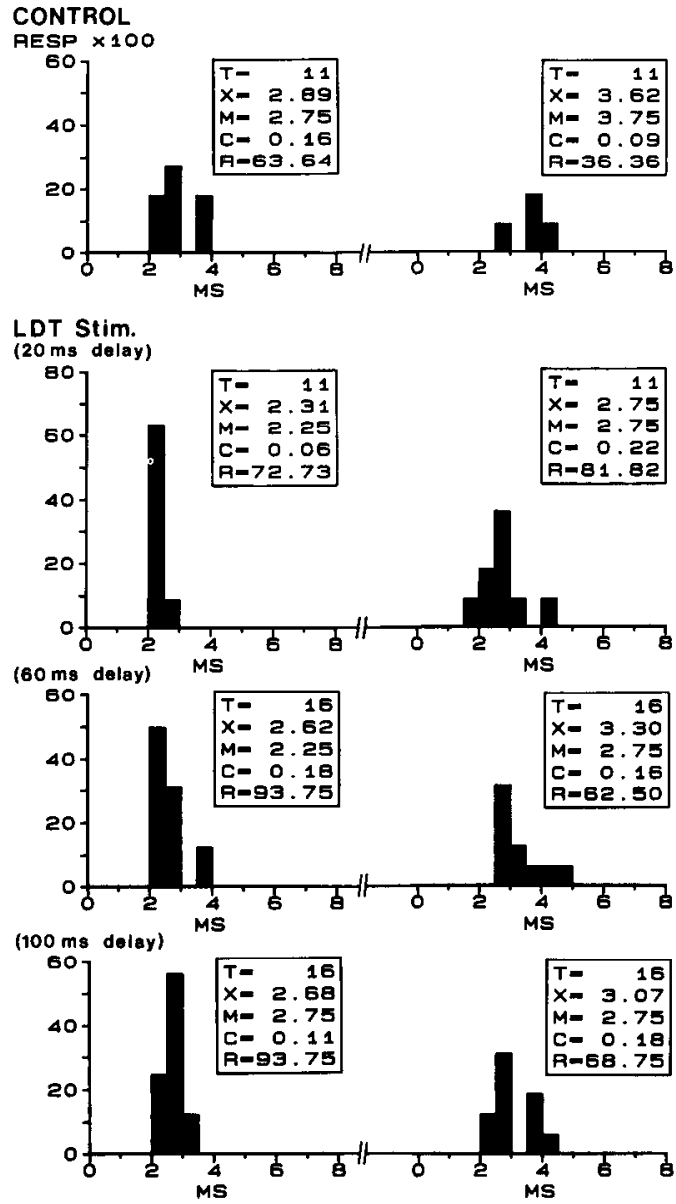

Figure 4. Effects of LDT stimulation on AT inhibitory processes. In this experiment, $2 \mathrm{MB}$ shocks, $40 \mathrm{msec}$ apart, were applied every $3 \mathrm{sec}$. Individual PSH were computed for the first and second shock. In the control situation, MB shocks were given without preceding LDT conditioning shocks. In the other series of trials, MB shocks were preceded by a brief LDT conditioning train ( 3 shocks at $300 \mathrm{~Hz}$ ) applied respectively 20,60 , and $100 \mathrm{msec}$ before the first testing shock. Symbols as in Figure 1. See text for explanations.

test the effect of LDT stimulation on the synaptic responsiveness and spontaneous discharge rate of AT cells. Intensity of MB shocks was first adjusted to evoke short-latency responses in $20-40 \%$ of the trials. Then, a baseline period of $80 \mathrm{sec}$ was obtained, after which a $1 \mathrm{sec}$ LDT train $(0.1 \mathrm{msec}$ pulses of 0.08 $\mathrm{mA}$ at $30 \mathrm{~Hz}$ ) was applied. Finally, the responsiveness fluctuations were monitored for at least $6 \mathrm{~min}$. The upper part of Figure 14 illustrates a pooled histogram of these 16 neurons. LDT trains induced a slight acceleration of the spontaneous discharge (black dots) and a slowly rising increase in synaptic responsiveness reaching up to $300 \% 50 \mathrm{sec}$ after the LDT train, and lasting more than $4 \mathrm{~min}$. Similar MB trains $(0.1 \mathrm{msec}$ pulses of 0.08 $\mathrm{mA}$ at $30 \mathrm{~Hz}$ for $1 \mathrm{sec}$ ) failed to mimic the potentiating effects of LDT trains (Fig. 14, bottom part).

In 9 out of the 10 tested cells, iontophoretic application of the muscarinic antagonist scopolamine suppressed the responsiveness potentiation induced by LDT trains. Four out of the 9 cells were held long enough for LDT influences to recover from scopolamine application. A typical experiment is illustrated in Figure 15. Scopolamine did not change the shape and amplitude of the action potentials. The blockade of LDT influences and 
Figure 5. Short-latency effects of LDT stimulation on AT neurons. $A-C$, Three different neurons recorded in urethaneanesthetized cats. $A$ and $C$, Effect of membrane hyperpolarization on LDTevoked depolarizations. The injection of hyperpolarizing current enhanced the depolarization induced by LDT stimulation and abolished the action potentials $(A 1-3)$ or FPPs $(C l-3)$ triggered on the crest of the depolarization. $C 4$ is an expansion of the trace in $C 2 . B$, Increase in apparent membrane conductance evoked by LDT stimulation. Two superposed sweeps showing the response of a cell at resting potential to a hyperpolarizing current pulse $(1 \mathrm{nA})$ without and with (arrows) a preceding LDT train. Note the decrease in pulse amplitude and augmentation of lowthreshold spike latency when the pulse is preceded by a LDT pulse train. In this and the following illustrations, the at the right of each trace. resting membrane potential is indicated

$$
\begin{aligned}
& A \\
& 1 \\
& 2 \\
& 3 \\
& \hline \\
& \hline
\end{aligned}
$$

A
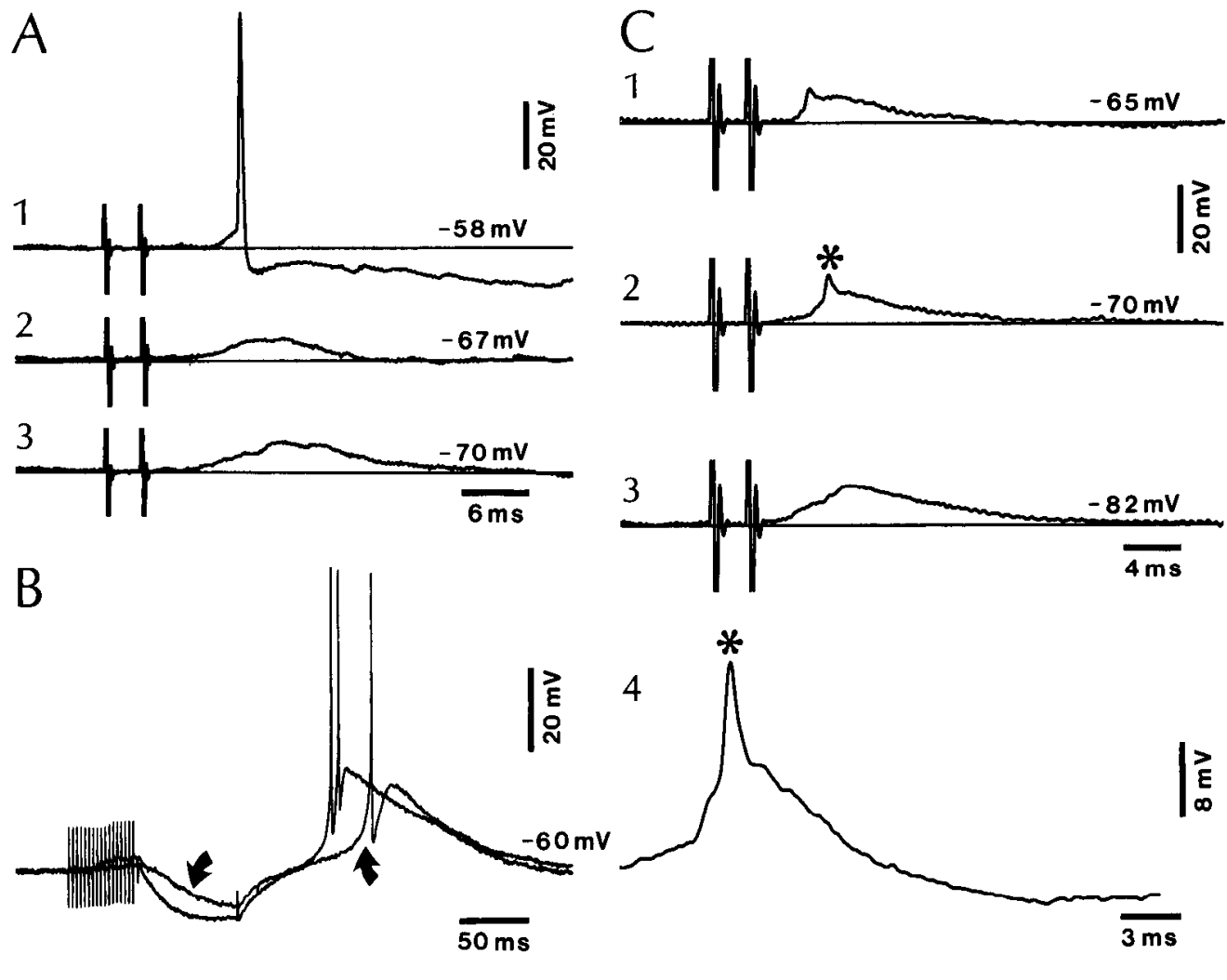

Figure 6. Long-lasting depolarization induced by LDT stimulation. LDT stimuli consisted of 3 shocks at $300 \mathrm{~Hz}$. Stimulation intensity was $0.08,0.07$. and $0.05 \mathrm{~mA}$ in the first, second, and third traces, respectively. Note the clusters of FPPs evoked by LDT shocks. Inset, Expansion of the rising phase of the LDT-induced depolarization (see arrow in first tracc).
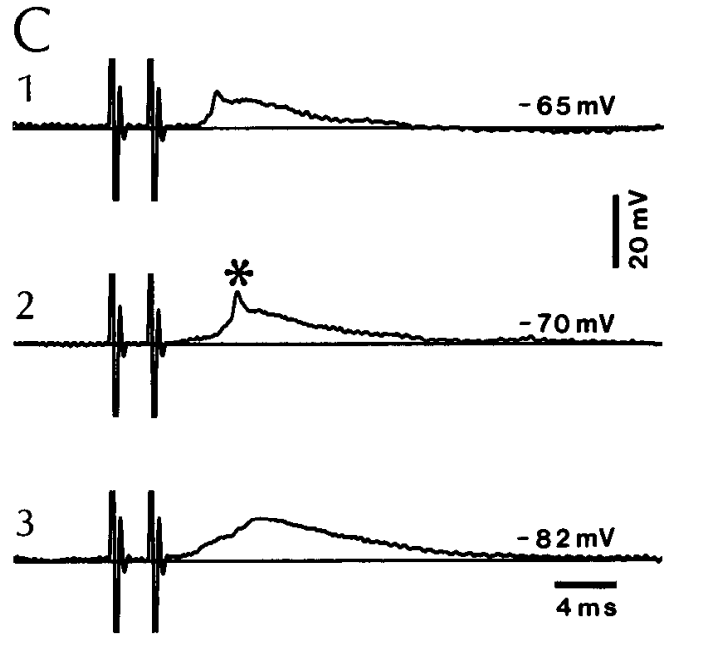


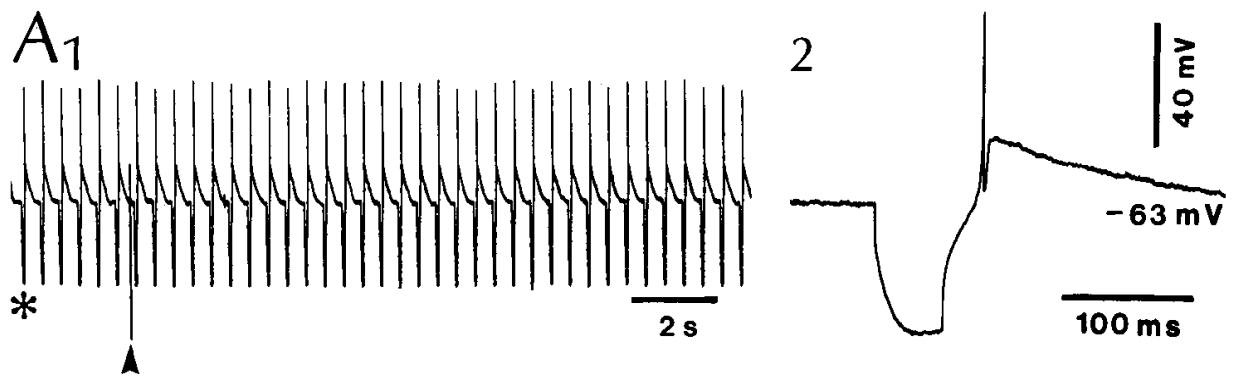

B

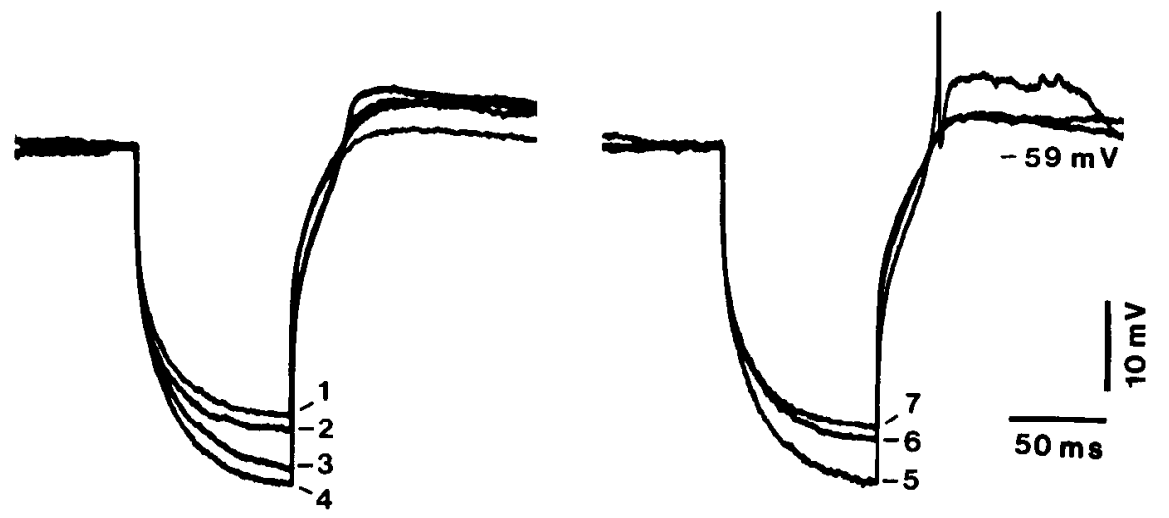

Figure 7. Slow and additive effects of LDT stimulation on the apparent input conductance of AT cells. $A$ and $B$, Two neurons at resting potential recorded in urethane-anesthetized cats. LDT trains consisted of 3 shocks at $300 \mathrm{~Hz}$ given every $20(A)$ or $3(B)$ sec. $A 2$ illustrates, at a higher speed, the cell response to a control hyperpolarizing current pulse of $2 \mathrm{nA}$ (asterisk in $A l$ ). In $B$, each LDT train was followed (after $200 \mathrm{msec}$ ) by a hyperpolarizing current pulse. Each trace represents the average of 5 sweeps taken at different times during the experiment: 1 control; $2-4,15,30$, and $45 \mathrm{sec}$, respectively, after the beginning of LDT trains; 5-7, 0, 15 and $30 \mathrm{sec}$, respectively, after the cessation of LDT shocks. When delivered slowly, LDT trains had no effect on the apparent input conductance $(A)$. With higher stimulation rates $(B)$, LDT trains gradually decreased the apparent membrane conductance of the cell.

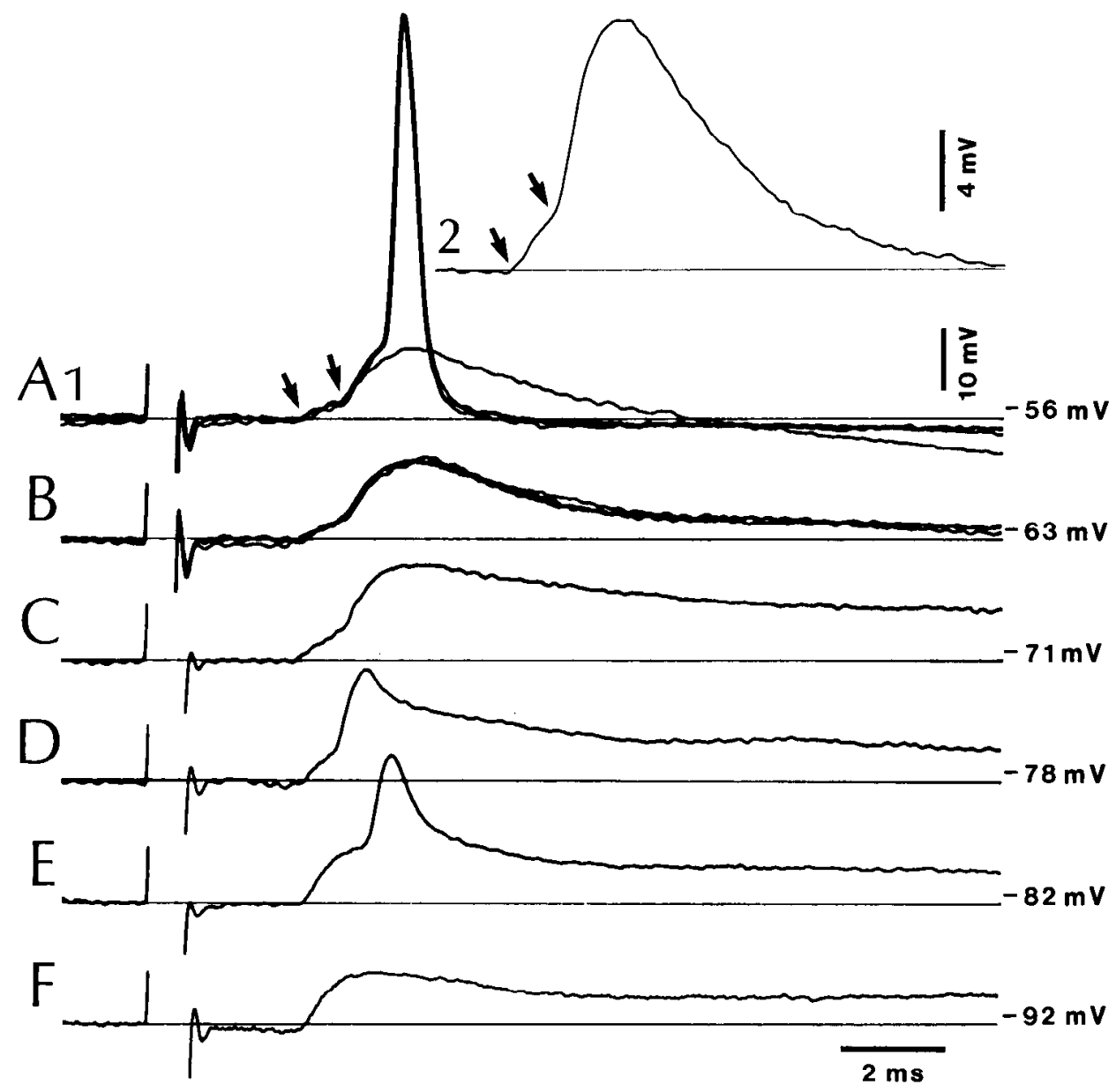

Figure 8. Two components of MBevoked responses. Effect of membrane hyperpolarization on the response evoked by MB stimulation in an AT neuron recorded under urethane anesthesia. $A l$ and $B, 5$ superposed sweeps. $A 2$ shows, at a higher speed, the sweep of $A 1$ without full action potential. $A r$ rows in $A$ point to the onset of the 2 components. Note the increasing amplitude of the first component with membrane hyperpolarization and the abolition of the second component in $F$. See text for explanations. 
Figure 9. Facilitation of FPP generation by MB-evoked EPSP following LDT stimulation. Intensity of MB testing shocks was adjusted to evoke only EPSPs in this AT neuron $(A)$. Then, 35 conditioning LDT trains ( 3 shocks at $300 \mathrm{~Hz}$, every $3 \mathrm{sec}$ ) preceding $\mathrm{MB}$ shocks by $200 \mathrm{msec}$ were delivered. $B$ shows the last 5 trials, and $C$ depicts 3 consecutive responses to MB stimulation taken $60 \mathrm{sec}$ after cessation of LDT trains. A $0.2 \mathrm{nA}$ hyperpolarizing current was injected in the cell throughout this experiment in order to avoid spike triggering by MB-evoked FPPs.

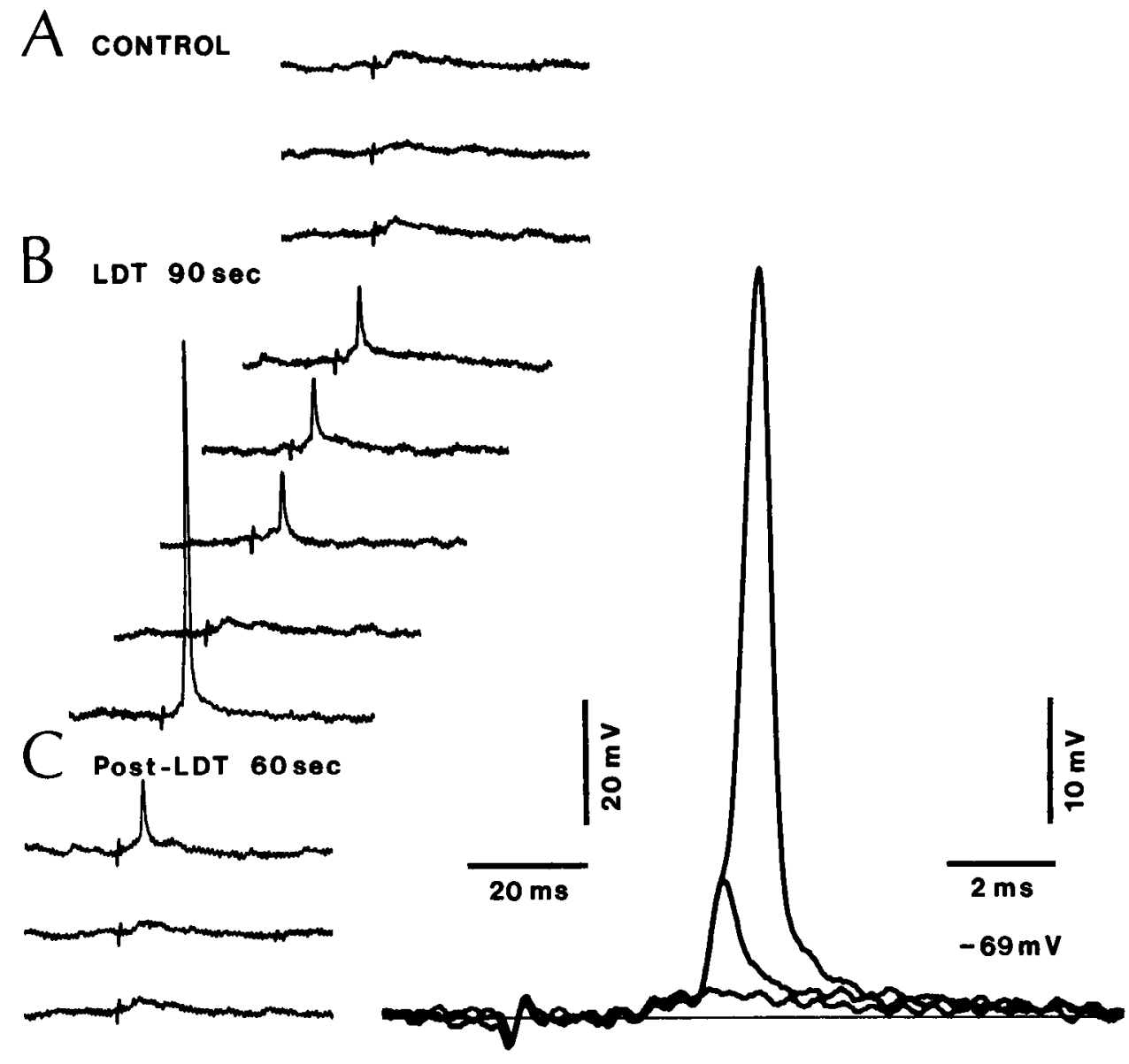

the responsiveness reduction induced by scopolamine outlasted the duration of the drug application: as much as 4-6 min was required for LDT influences to recover (see legend of Fig. 15).

In order to evaluate the possible involvement of basal forebrain projections to the thalamus (Steriade et al., 1987; Parent et al., 1988) or corticothalamic afferents in this phenomenon, similar tests were carried out in 11 cells after interruption of cortical and basal forebrain inputs to the AT complex (see Materials and Methods). Figure 16 illustrates the results of these experiments. The prolonged LDT-induced enhancement of synaptic responsiveness to MB stimuli persisted, but no significant change in spontaneous discharge rates was observed.

\section{Discussion}

We have shown that LDT stimulation excites AT cells at short latencies and increases their responsiveness to both ortho- and antidromic stimuli for prolonged periods of time, without interfering with local inhibitory processes.

\section{Short-latency activation of AT neurons by LDT stimulation}

Various lines of evidence suggest that the short-latency synaptic excitation of AT neurons induced by LDT stimulation resulted from the activation of cholinergic LDT cells projecting to the AT complex.

First, recent studies combining retrograde tracing methods and immunohistochemical techniques have shown, in both rat (Satoh and Fibiger, 1986; Hallenger et al., 1987) and cat (Steriade et al., 1988), that most cells of the mesopontine tegmentum projecting to the AT complex are located in the LDT nucleus, the majority of them staining positively for choline acetyltransferase, the rate-limiting synthetic enzyme of $\mathrm{ACh}$. Moreover, these experiments also revealed that a few raphe dorsalis and locus coeruleus neurons project to the AT nuclei. However, it is unlikely that LDT-induced excitations resulted from the coactivation of monoaminergic fibers since AT cells could still be orthodromically activated by LDT stimulation after monoamine depletion by reserpine treatment.

Second, the latencies of LDT-evoked synaptic excitations are consistent with the relatively slow conduction velocities of LDT and $\mathrm{PB}$ fibers, as estimated from the antidromic invasion latency of these neurons following thalamic stimulation (Ahlsén, 1984; Grant et al., 1988). Although the latency of LDT-evoked effects fits well with the slow conduction velocity of LDT fibers, another explanation could be considered for this phenomenon. A population of $\mathrm{MB}$ cells has a bifurcating axon with an ascending branch toward the AT complex and a descending one toward the brain stem (Van der Kooy et al., 1978; Kuypers et al., 1980; Takeuchi et al., 1985). These axons could have been backfired by LDT stimuli, thereby orthodromically activating their AT target by axon reflex. However, the time course of the shortlatency responses to $\mathrm{MB}$ and LDT stimulation is completely different. Subthreshold MB stimuli evoked a fast-rising, shortlasting response ( $<8 \mathrm{msec}$ ) interrupted by a deep IPSP, whereas LDT responses rose slowly, had a mean duration of $24 \mathrm{msec}$, and were usually not followed by an IPSP. These observations also argue against another possibility, namely, that LDT-evoked 


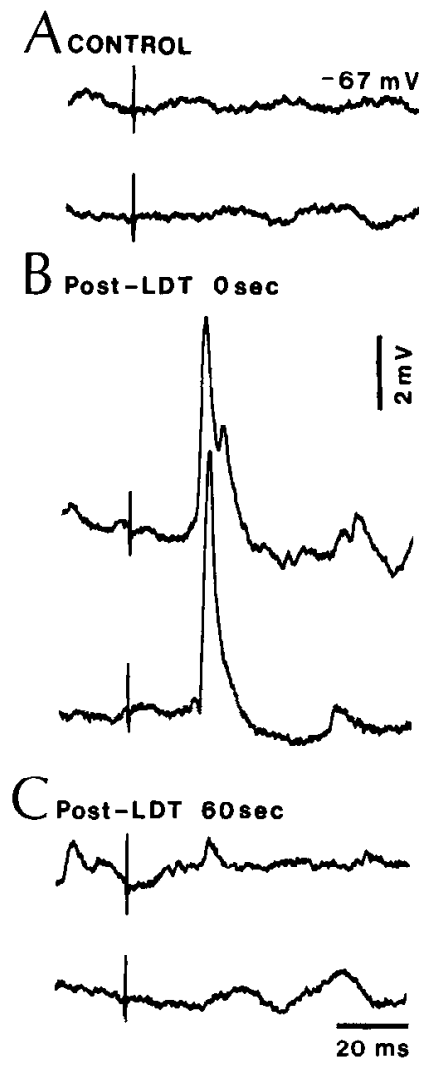

Figure 10. Facilitation of cortically elicited FPPs by LDT conditioning trains. In $A$, the intensity of cortical shocks was adjusted below the threshold for spike triggering. Between $A$ and $B, 13$ LDT trains $(3$ shocks at $300 \mathrm{~Hz}$ every $3 \mathrm{sec}$ ) were applied. Immediately following the $13 \mathrm{LDT}$ trains, most cortical shocks elicited an FPP. Sixty seconds after cessation of LDT stimulation, the probability of FPP generation by cortical shocks returned to control values. A $0.3 \mathrm{nA}$ hyperpolarizing current was injected throughout this experiment to avoid spike triggering by cortically evoked FPPs.

short-latency excitations resulted from the synaptic activation of MB cells by LDT fibers.

No definitive conclusion can be drawn concerning the receptors involved in these short-latency effects of LDT stimulation. Nevertheless, the available evidence argues in favor of a nicotinic response. First, large densities of nicotinic receptors have been found in the AT complex (Clarke et al., 1985; Friedman et al., 1985). In addition, $\mathrm{Hu}$ et al. (1988) have recently shown that iontophoretic application of nicotinic antagonists can suppress the short-latency response of LG neurons to the stimulation of the cholinergic cells located in the peribrachial area. Morever, McCormick and Prince (1987) have reported that pulse application of $A C h$ to $L G$ neurons evokes a fast and transient depolarization sensitive to nicotinic blockers.

\section{Enhancement of $A T$ responsiveness by $L D T$ stimulation}

In this study, LDT conditioning trains enhanced the responsiveness of AT cells to both ortho- and antidromic stimuli in undrugged and reserpine-treated cats. The persistence of LDT enhancing effects after monoamine depletion suggests that monoaminergic inputs are not responsible for these changes in AT responsiveness. Similarly, it is unlikely that polysynaptic effects channelled to the AT complex through MB or cortical

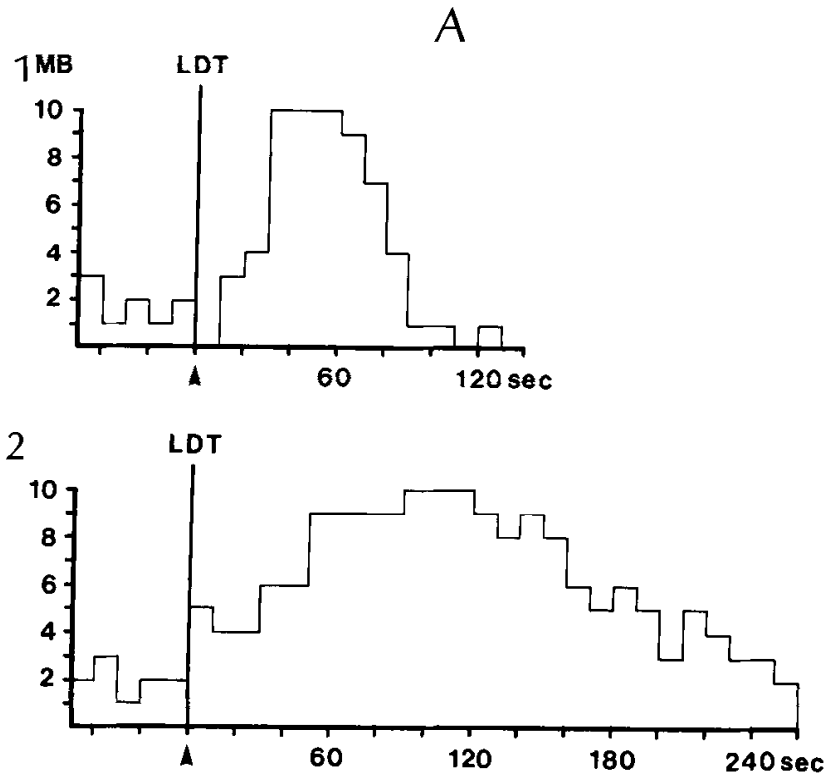

B

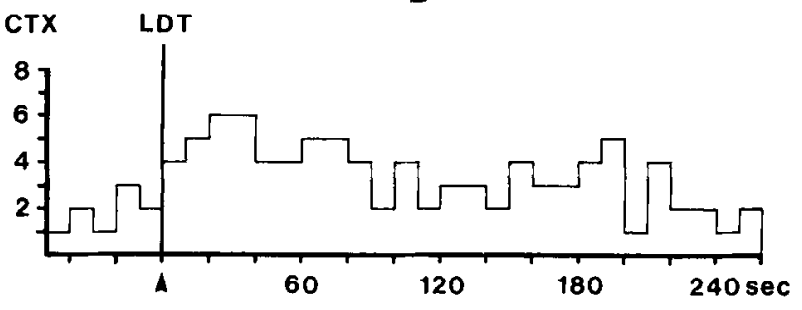

Figure 11. Enhancement of AT synaptic responsiveness by LDT conditioning trains. $A$ and $B$, Two cells recorded extracellularly in reserpinetreated cats: $\mathrm{MB}(A)$ and presubicular cortex $(B)$ testing shocks. A unique LDT conditioning train $(30 \mathrm{~Hz})$ having a duration of $0.5 \mathrm{sec}(A I)$ and $1 \sec (A 2, B)$ was applied at time 0 (arrow head). Testing shocks were given every second, and the number of short-latency responses out of 10 trials was calculated (ordinate). Ten sccond bins (abscissa). See text for explanations.

afferents caused these increases in responsiveness since direct stimulation of the MB or cingular cortex failed to mimic the effects of LDT trains. Two possibilities remain: a direct projection from the LDT nucleus to the AT complex or a bisynaptic pathway relayed in the basal forebrain (Steriade et al., 1987; Parent et al., 1988). Since LDT influences over AT responsiveness were found to resist transections interrupting the fibers coursing from the basal forebrain to the AT complex, we conclude that direct projections from the LDT nucleus to the AT nuclei mediate these modulations in excitability. In agreement with this conclusion and the fact that most LDT cells projecting to the AT complex are cholinergic (Satoh and Fibiger, 1986; Hallenger et al., 1987; Steriade et al., 1988), iontophoretic application of the muscarinic blocker scopolamine abolished the long-lasting responsiveness potentiation induced by LDT trains. In contrast with the previously reported effects of ACh on neurons at other cerebral sites (Benardo and Prince, 1982; Halliwell and Adams, 1982; Madison et al., 1987), LDT stimulation generally induced a slowly developing, long-lasting decrease in apparent membrane conductance with no concomitant change in the membrane potential of AT cells. Moreover, the enhancing effects of LDT stimulation on the orthodromic responsiveness 


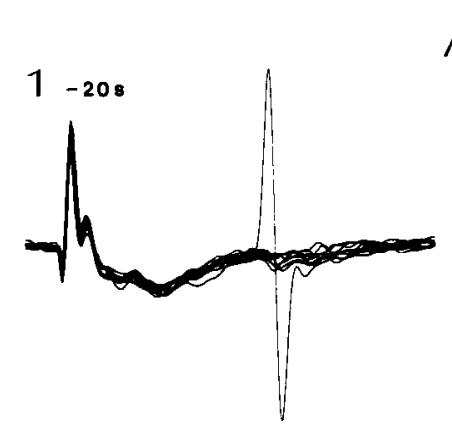

A
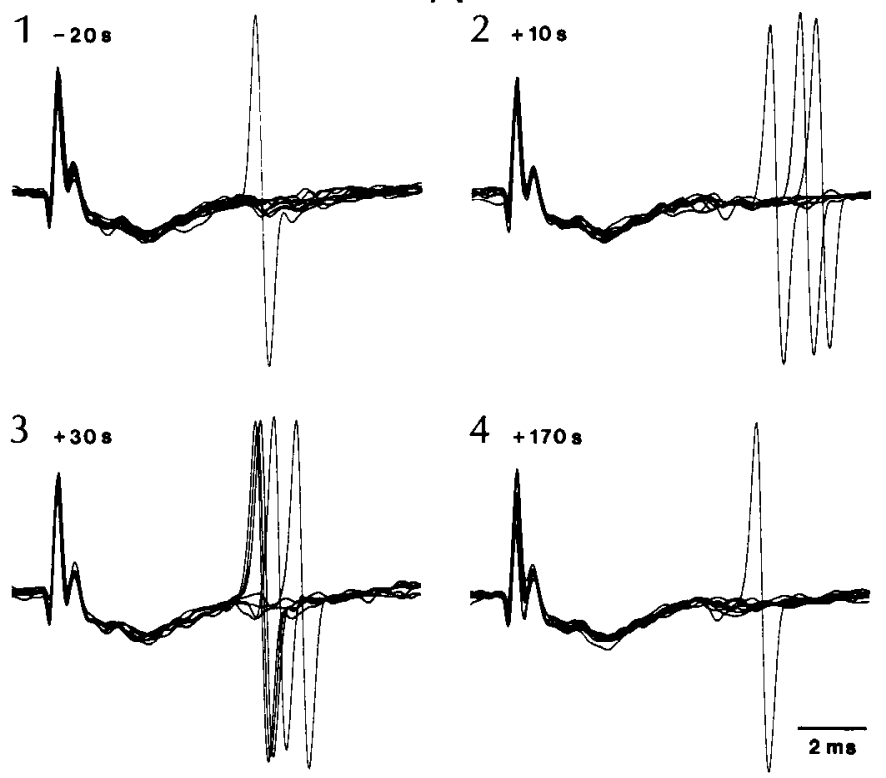

$4+170$

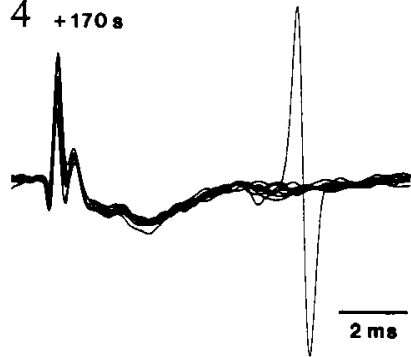

B

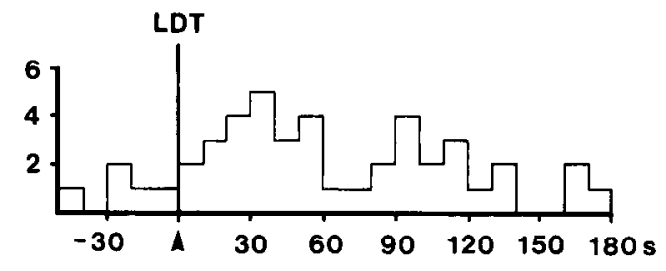

Figure 12. Increased synaptic responsiveness following a single LDT conditioning train. Same type of experiment as in the preceding illustration. Extracellularly recorded neuron in a reserpine-treated cat. $A$, Four groups of 10 superimposed oscilloscopic traces showing the cells' response to test shocks applied to the MB every second. Temporal coordinates are given for each group of oscilloscopic traces. These indications can be related to the histogram $(B)$ showing how the responsiveness of this AT neuron fluctuated during the experiment. Ordinate and abscissa as in Figure 11. A single $1 \sec$ LDT train $(30 \mathrm{~Hz})$ was applied at time 0 (arrowhead).

of AT cells could also be elicited when no change in membrane conductance was apparent. In only $8 \%$ of the tested cells did LDT stimulation evoke a long-lasting depolarization.

It is known that in other parts of the nervous system, $\mathrm{ACh}$ application can depolarize and excite the tested cells by the closure of various K conductances (See Siggins and Gruol, 1986) If this mechanism underlies the effects of LDT stimulation on AT cells, these conductances must have a dendritic location since no change in membrane potential was observed at the somatic level. In agreement with this interpretation, the probability of FPP being triggered by orthodromic shocks was increased during periods of LDT stimulation. It has been reported that $\mathrm{ACh}$ applied to hippocampal pyramidal cells neurons in vitro promotes tetrodotoxin (TTX)-resistant spikes by depolarizing current ramps (Gahwiler, 1984). Since ACh depresses calcium currents in hippocampal pyramidal cells (Gahwiler and Brown, 1987), the facilitation of TTX-resistant spikes by ACh must be a consequence of the decrease in membrane conductance induced by ACh. Another possibility would be that LDT stimulation provokes the closure of chloride leakage channels.
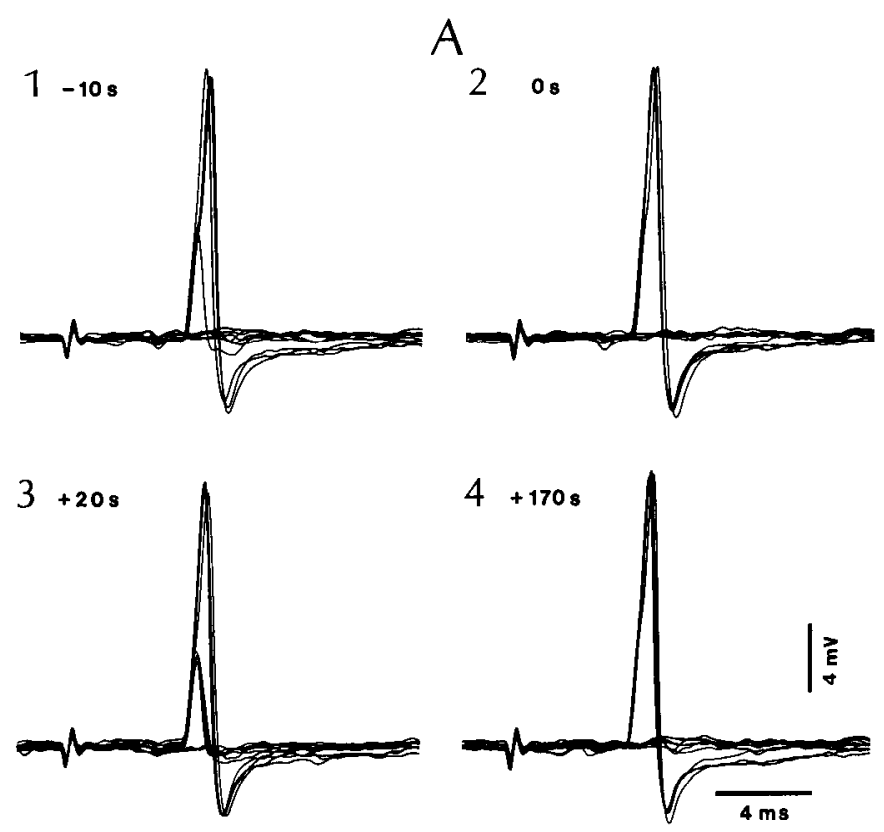

B

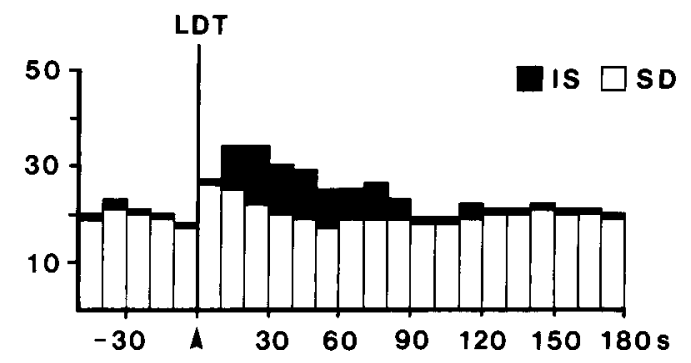

Figure 13. Increased antidromic responsiveness induced by LDT conditioning trains. Same type of experiment as in Figure 12 except that testing stimuli were applied to the presubicular cortex and that $B$ depicts the combined results of 5 experiments.

This mechanism would cause virtually no change in membrane potential.

Finally, the presence of muscarinic receptors on fibers ending in the AT nuclei (Sikes and Vogt, 1987) opens the possibility that presynaptic mechanisms could be involved in the effects of LDT stimulation. However, the facilitatory effects of LDT stimuli on antidromically evoked discharges suggest that postsynaptic mechanisms are involved.

\section{Time course of LDT-induced enhancement of $A T$ responsiveness}

In previous attempts to study the effects of brain-stem stimulation on thalamic operations, investigators relied on a conditioning-testing paradigm. Usually, brief, high-frequency MRF trains followed at various delays by a testing stimulus were applied repeatedly $(0.3-1 \mathrm{~Hz})$, implicitly assuming that the effects of the successive conditioning trains were short-lasting and nonadditive. Apparently no provision was made for possible order effects in the presentation of the various conditioningtesting intervals (Nakai and Domino, 1968; Doty et al., 1973; Singer, 1973; Foote et al., 1974). The results of the present study indicate that repetitive LDT stimulation does have cumulative 

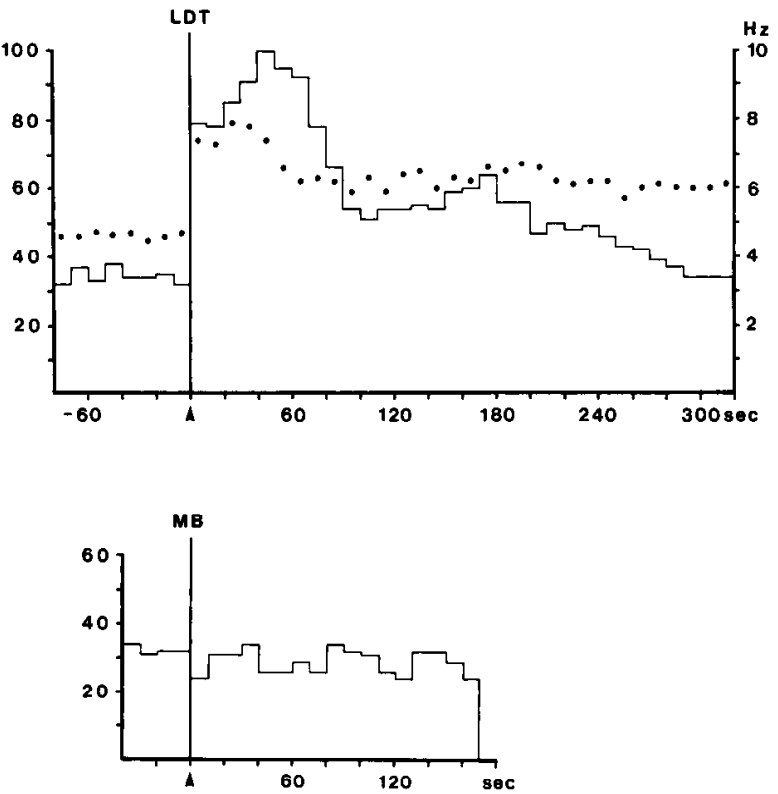

Figure 14. Effect of LDT and MB conditioning trains $(30 \mathrm{~Hz}, 1 \mathrm{sec})$ on the synaptic responsiveness of 16 AT cells to MB stimulation. Testing shocks were given every second, and the number of short-latency responses out of 10 trials was calculated (ordinate) by $10 \mathrm{sec}$ bins ( $a b$ scissa). For each cell, a unique $1 \mathrm{sec}$ LDT train $(30 \mathrm{~Hz})$ was applied at time 0 (arrowhead). The number of responses was averaged bin by bin, and the values were normalized so that the bin with the maximum number of counts was equal to 100 . In the upper graph, the discharge rate (black dots) of the cell was measured in $10 \mathrm{sec}$ bins (right-hand ordinate); evoked discharges and artifacts were deleted.

effects on the responsiveness of AT cells. With the stimulating rate used here (1 LDT train every $3 \mathrm{sec}$ ), the responsiveness enhancement reached a plateau $2 \mathrm{~min}$ after the onset of the tests and persisted up to $1 \mathrm{~min}$ following the interruption of LDT trains. However, the slow time course of LDT-evoked increases in responsiveness was not entirely due to the slow stimulation rate since the increases in synaptic responsiveness induced by a unique $1 \mathrm{sec}$ LDT train (at $30 \mathrm{~Hz}$ ) took as much as $50 \mathrm{sec}$ to reach their peak and lasted for $3 \mathrm{~min}$.

Because of the rapid degradation of $\mathrm{ACh}$ molecules by acetylcholinesterase in nervous tissue (see Rosenberry, 1975), it is unlikely that the slow time course of LDT effects resulted from a slow buildup of $\mathrm{ACh}$ in the vicinity of the recorded cells. Then, if $\mathrm{ACh}$ is responsible for these effects, the involvement of intracellular events outlasting the period of LDT stimulation must be postulated. The presence of various peptides in LDT cells (Vincent et al., 1983; Sutin and Jacobowitz, 1988) suggests that various "unconventional" mechanisms could play an important role. For instance, since $\mathrm{ACh}$ is colocalized with substance $P$ in $40 \%$ of LDT neurons (Vincent et al., 1983), it is possible that $\mathrm{ACh}$ and substance $\mathrm{P}$ act cooperatively to produce postsynaptic effects.

\section{Effect of LDT stimulation on AT inhibitory processes}

Being devoid of RE afferents (Steriade et al., 1984; Paré et al., 1987; Velayos et al., 1989), AT cells are only subjected to feedforward inhibition mediated by local-circuit cells. In this study, it was found that LDT afferents exert a dual influence on AT inhibitory processes, as assessed by a double-shock paradigm.
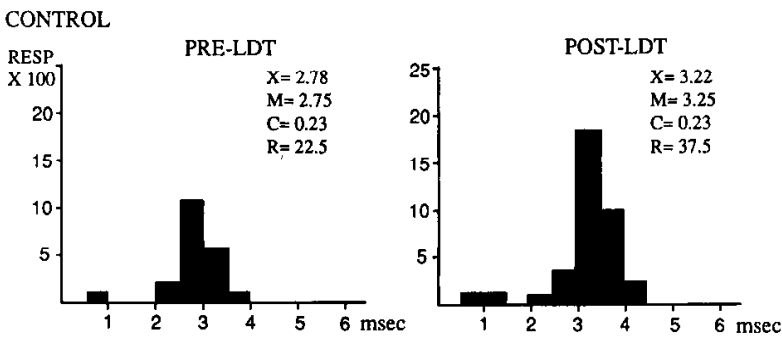

SCOPOLAMINE
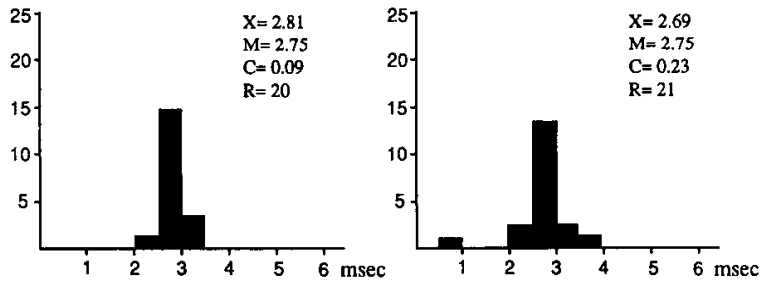

RECOVERY
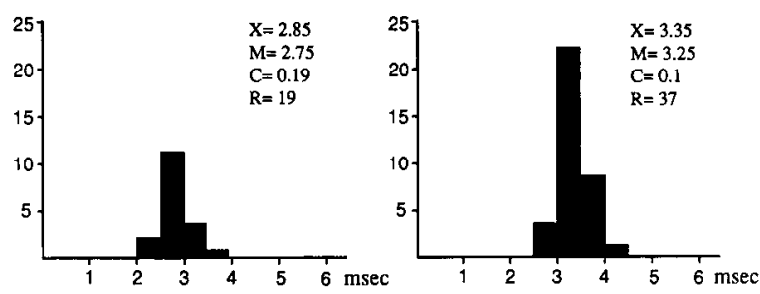

Figure 15. Abolition of the LDT-induced responsiveness potentiation by iontophoretic application of the muscarinic blocker scopolamine to an AT neuron. Testing shocks were applied to the MB. Poststimulus histograms were constructed by computing the responsiveness of the cell to the 80 trials immediately preceding and following the LDT train. Scopolamine ejection ( $30 \mathrm{nA}$ ) began $140 \mathrm{sec}$ before the LDT train and lasted $320 \mathrm{sec}$. With the exception of the ejection period, a retaining current of $10 \mathrm{nA}$ was applied through the barrel containing scopolamine. Seven minutes elapsed between the LDT train of the first (Control) and second test (Scopolamine). Ten minutes elapsed between the LDT train of the second (Scopolamine) and third (Recovery) test. For symbols, see legend of Figure 1.

During and immediately after LDT-evoked excitations, AT cells appeared to be disinhibited. However, when testing shocks were applied well after the direct excitation induced by LDT stimulation, inhibitory processes returned to control values. Therefore, LDT stimulation did not completely disinhibit relay cells of the AT complex.

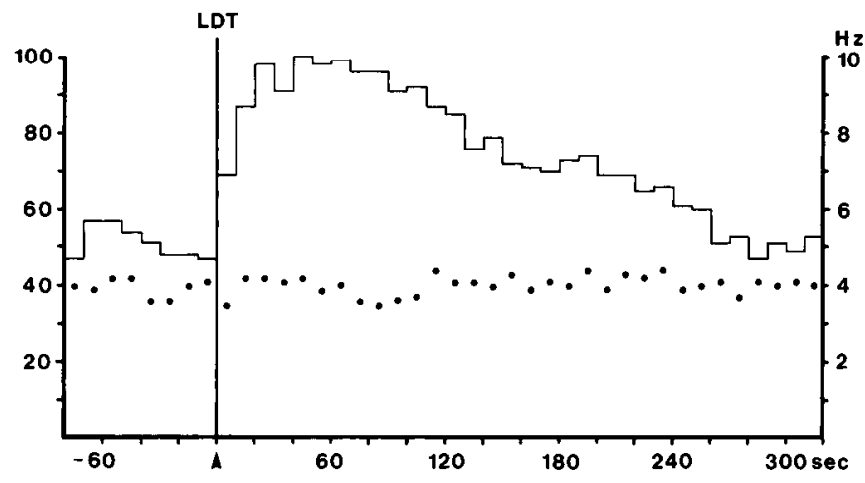

Figure 16. Effect of LDT stimulation on the synaptic responsiveness of 11 AT cells deprived of cortical input by appropriate transections. For details, see legend of Figure 14. 
While there is a general consensus concerning the effects of MRF stimulation and ACh iontophoresis on RE neurons and recurrent inhibition (Ben-Ari et al., 1976; Godfraind, 1976; Dingledine and Kelly, 1977), brain-stem cholinergic influences on local-circuit cells remain controversial. Studies reporting decreased feedforward inhibitory pressures following ACh iontophoresis or MRF stimulation were performed in barbiturateanesthetized cats (Ahlsén et al., 1984; Francesconi et al., 1988), whereas those reporting intact or increased local inhibitory gradients (Sillito et al., 1983; Eysel et al., 1986) were carried out under different anesthetic conditions. We therefore suggest that barbiturate anesthetics distort the normal action of ACh on local-circuit cells. This hypothesis is supported by the fact that other aspects of thalamic responses to $\mathrm{ACh}$ application and MRF stimulation are sensitive to these drugs (Eysel et al., 1986; Pape and Eysel, 1988) and by the demonstration of a negative heterotropic interaction between barbiturate and cholinergic binding sites on the nicotinic ACh receptors (Dodson et al., 1987).

However, a recent intracellular study performed in vitro reported that ACh hyperpolarizes morphologically identified LG interneurons (McCormick and Pape, 1988). The problem raised by this study is that interneurons were initially identified by the short duration of their action potentials. Besides, the ACh-induced hyperpolarization may be confined to the soma, without affecting the intraglomerular dendrodendritic synapses that are thought to underly discriminative processes.

\section{Functional considerations}

The long-lasting enhancement of synaptic responsiveness induced by LDT stimulation differs from posttetanic potentiation (PTP) and long-term potentiation (LTP) in various respects. For instance, in the case of the PTP and LTP, the potentiation is generally restricted to the stimulated pathway, whereas after LDT stimulation, it affects AT responses to cortical and subcortical inputs. Furthermore, LDT effects cannot be mimicked by high-frequency stimulation applied to the testing pathways.

Although iontophoretically applied ACh had previously been shown to potentiatc the excitability of cortical cells for prolonged periods of time (Woody et al., 1978; Metherate et al., 1987, 1988), to the best of our knowledge, such effects of ACh, and especially those of synaptically released $\mathrm{ACh}$, had never been demonstrated in the dorsal thalamus. Whether this is a peculiarity of the AT complex remains to be investigated in other thalamic nuclei. Nevertheless, the slow and cumulative effects of LDT afferents disclosed in this study are consistent with the long-term excitability changes characterizing shifts in states of vigilance. In fact, there is a good correspondence between the discharge rate of most LDT cells (current experiments) and the responsiveness of AT cells during the sleep-waking cycle (Paré et al., 1989), both increasing in W and decreasing in S. Thus, by increasing the ability of AT cells to transfer incoming signals to the cerebral cortex while preserving the local inhibitory processes required for analytical processing, LDT afferents set the stage for adaptive pursuits.

\section{References}

Ahlsén, G. (1984) Brain stem neurones with differential projection to functional subregions of the dorsal lateral geniculate complex in the cat. Neuroscience 12:817-838.

Ahlsén, G., S. Lindström, and F. S. Lo (1984) Inhibition from the brain stem of inhibitory interneurones of the cat's dorsal lateral geniculate nucleus. J. Physiol. (Lond.) 347: 593-609.
Benardo, L. S., and D. A. Prince (1982) Ionic mechanisms of cholinergic excitation in mammalian hippocampal pyramidal cells. Brain Res. 249: 333-344.

Ben-Ari, Y., R. Dingledine, I. Kanazawa, and J. S. Kelly (1976) Inhibitory effects of acetylcholine on neurones in the feline nucleus reticularis thalami. J. Physiol. (Lond.) 261: 647-671.

Carlsson, A. (1966) Drugs which block the storage of 5-hydroxytryptamine and related amines. In Handbook of Experimental Pharmacology, O. Eichler and A. Farah, eds., pp. 529-592, Springer, New York.

Clarke, P. B. S., R. D. Schwartz, S. M. Paul, C. B. Pert, and A. Pert (1985) Nicotinic binding in rat brain: Autoradiographic comparison of $\left({ }^{3} \mathrm{H}\right)$ acetylcholine, $\left({ }^{3} \mathrm{H}\right)$ nicotine, and $\left({ }^{125} \mathrm{I}\right)-\alpha$-bungarotoxin. J. Neurosci. 5: 1307-1315.

Dingledine, R., and J. S. Kelly (1977) Brain stem stimulation and the acetylcholine-evoked inhibition of neurones in the feline nucleus reticularis thalami. J. Physiol. (Lond.) 271: 135-154.

Dodson, B. A., L. M. Braswell, and K. W. Miller (1987) Barbiturates bind to an allosteric regulatory site on nicotinic acetylcholine receptorrich membranes. Mol. Pharmacol. 32: 119-126.

Dolabela de Lima, A., and W. Singer (1987) The brainstem projection to the lateral geniculate nucleus in the cat: Identification of cholinergic and monoaminergic elements. J. Comp. Neurol. 259: 92-121.

Doty, R. W., P. D. Wilson, J. R. Bartlett, and J. P. Pecci-Saaverda (1973) Mesencephalic control of lateral geniculate nucleus in primates. I. Electrophysiology. Exp. Brain Res. 18: 189-203.

Eysel, U. T., H. C. Pape, and R. V. Schayck (1986) Excitatory and differential disinhibitory actions of acetylcholine in the lateral geniculate nucleus of the cat. J. Physiol. (Lond.) 370: 233-254.

Foote, W. E., R. J. Maciewicz, and J. P. Mordes (1974) Effect of midbrain raphe and lateral mesencephalic stimulation on spontaneous and evoked activity in the lateral geniculate nucleus of the cat. Exp. Brain Res. 19: 124-130.

Francesconi, W., C. M. Müller, and W. Singer (1988) Cholinergic mechanisms in the reticular control of transmission in the cat lateral geniculate nucleus. J. Neurophysiol. 59: 1690-1718.

Friedman, D. P., P. B. S. Clarke, J. B. O'Neill, and A. Pert (1985) Distribution of nicotinic and muscarinic cholinergic receptors in monkey thalamus. Soc. Neurosci. Abstr. 11: 1054.

Gahwiler, B. H. (1984) Facilitation by acetylcholine of tetrodoxinresistant spikes in rat hippocampal pyramidal cells. Neuroscience 11 : 381-388.

Gahwiler, B. H., and D. A. Brown (1987) Muscarine affects calciumcurrents in rat hippocampal pyramidal cells in vitro. Neurosci. Lett. 76: 301-306.

Godfraind, J. M. (1976) Further studies on perigeniculate neurons: Effects of glutamate, acetylcholine and somatic stimulation. Arch. Int. Pharmacodyn. 223: 166-167.

Grant, S. J., D. A. Highfield, and T. Piser (1988) Electrophysiology of putative $\mathrm{CH} 6$ cholinergic neurons in the laterodorsal tegmental nucleus. Soc. Neurosc. Abstr. 14: 905.

Hallenger, A. E., A. I. Levey, H. J. Lee, D. B. Rye, and B. H. Wainer (1987) The origin of cholinergic and other subcortical afferents to the thalamus in the rat. J. Comp. Neurol. 262: 105-124.

Halliwell, J. V., and P. R. Adams (1982) Voltage-clamp analysis of muscarinic excitation in hippocampal neurons. Brain Res. 250:7192.

Herkenham, M. (1978) The connections of the nucleus reuniens thalami: Evidence for a direct thalamo-hippocampal pathway in the rat. J. Comp. Neurol. 177: 589-610.

Hu, B., D. Bouhassira, M. Steriade, and M. Deschênes (1988) The blockage of ponto-geniculo-occipital waves in the cat lateral geniculate nucleus by nicotinic antagonists. Brain Res. 473: 394-397.

Hu, B., M. Steriade, and M. Deschênes (1989a) The effects of brainstem peribrachial stimulation on perigeniculate neurons: The blockade of spindle waves. Neuroscience $31: 1-12$.

Hu, B., M. Steriade, and M. Deschênes (1989b) The effects of brainstem peribrachial stimulation on neurons of the lateral geniculate nucleus. Neuroscience 31: 13-24.

Jahnsen, H., and R. Llinás (1984a) Electrophysiological properties of guinea-pig thalamic neurones: An in vitro study. J. Physiol. (Lond.) 349: 205-226.

Jahnsen, H., and R. Llinás (1984b) Ionic basis for the electroresponsiveness and oscillatory properties of guinea-pig thalamic neurones in vitro. J. Physiol. (Lond.) 349: 227-247. 
Kaufman, E. F., and A. C. Rosenquist (1985) Afferent connections of the thalamic intralaminar nuclei in the cat. Brain Res. 335: 281-296.

Kayama, Y., M. Takagi, and T. Ogawa (1986) Cholinergic influence of the laterodorsal tegmental nucleus on neuronal activity in the rat lateral geniculate nucleus. J. Neurophysiol. 56: 1297-1309.

Kuypers, H. G. J. M., M. Bentivoglio, C. E. Castman-Berrevoets, and A. T. Bharos (1980) Double retrograde neuronal labeling through divergent axon collaterals, using two fluorescent tracers with the same excitation wavelength which label different features of the cell. Exp. Brain Res. 40: 383-392.

Levey, A. I., A. E. Hallenger, and B. H. Wainer (1987) Choline acetyltransferase immunoreactivity in the rat thalamus. J. Comp. Neurol. 257: 317-332.

Llinás, R., and C. Nicholson (1971) Electrophysiolugical properties of dendrites and somata in alligator Purkinje cells J. Neurophysiol. 34: 532-551.

Madison, D. V., B. Lancaster, and R. A. Nicoll (1987) Voltage clamp analysis of cholinergic action in the hippocampus. J. Neurosci. 7 : 733-741.

Marshall, K. C., and H. McLennan (1972) The synaptic activation of neurones of the feline ventrolateral thalamic nucleus: Possible cholinergic mechanisms. Exp. Brain Res. 15: 472-483.

Mash, D. C., and L. T. Potter (1986) Autoradiographic localization of $\mathrm{M} 1$ and $\mathrm{M} 2$ muscarinic receptors in the rat brain. Neuroscience 19: $551-564$.

McCormick, D. A., and H. C. Pape (1988) Acetylcholine inhibits identified interneurons in the cat lateral geniculate nucleus. Nature 334: 246-248.

McCormick, D. A., and D. A. Prince (1986) Acetylcholine induces burst firing in thalamic reticular neurones by activating a potassium conductance. Nature 319: 402-405.

McCormick, D. A, and D. A. Prince (1987) Actions of acetylcholine in the guinea pig and cat medial and lateral geniculate nuclei. J. Physiol. (Lond.) 392: 147-165.

Metherate, R., N. Tremblay, and R. W. Dykes (1987) Acetylcholine permits long-term enhancement of neuronal responsiveness in cat primary somatosensory cortex. Neuroscience 22: 75-81.

Metherate, R., N. Tremblay, and R. W. Dykes (1988) Transient and prolonged effects of acetylcholine on responsiveness of cat somatosensory cortical neurons. J. Neurophysiol. 59: 1253-1276.

Montero, V. (1987) Ultrastructural identification of synaptic terminals from the axon of type 3 interneurons in the cat lateral geniculate nucleus. J. Comp. Neurol. 264: 268-283.

Mulle, C., M. Steriade, and M. Deschênes (1985) Absence of spindle oscillations in the cat anterior thalamic nuclei. Brain Res. 334: 165168.

Nakai, Y., and E. F. Domino (1968) Reticular facilitation of visually evoked responses by optic tract stimulation before and after enucleation. Exp. Neurol. 22: 532-544.

Ogawa, T. (1963) Midbrain reticular influences upon single neurons in lateral geniculate nucleus. Science $139:$ 343-344.

Pape, H. C., and U. T. Eysel (1988) Cholinergic excitation and inhibition in the visual thalamus of the cat-influences of cortical inactivation and barbiturate anesthesia. Brain Res. 440: 79-86.

Paré, D., M. Steriade, M. Deschênes, and G. Oakson (1987) Physiological characteristics of anterior thalamic nuclei, a group devoid of inputs from reticular thalamic nucleus. J. Neurophysiol. 57: 16691685.

Paré, D., Y. Smith, A. Parent, and M. Steriade (1988) Projections of brainstem core cholinergic and non-cholinergic neurons of cat to intralaminar and reticular thalamic nuclei. Neuroscience $25: 69-86$.

Paré, D., D. Bouhassira, G. Oakson, and S. Datta (1989) Spontaneous and evoked activities of anterior thalamic neurons during waking and sleep states. Exp. Brain Res. (in press).

Parent, A., D. Paré, Y. Smith, and M. Steriade (1988) Basal forebrain cholinergic and non-cholinergic projections to the thalamus and brainstem in cats and monkeys. J. Comp. Neurol. 277: 281-301.

Phillis, J. W., A. K. Tebecis, and D. H. York (1967) A study of cholinoceptive cells in the lateral geniculate nucleus. J. Physiol. (Lond.) 192: 695-713.

Robertson, R. T., and S. S. Kaitz (1981) Thalamic connections with limbic cortex. I. Thalamocortical projections. J. Comp. Neurol. 195. 501-525.
Rosenberry, T. L. (1975) Acetylcholinesterase. Adv. Enzymol. 43: 103-213.

Satoh, K., and H. C. Fibiger (1986) Cholinergic neurons of the laterodorsal tegmental nucleus: Efferent and afferent connections. J. Comp. Neurol. 253: 277-302

Siggins, G. R., and D. L. Gruol (1986) Mechanisms of transmitter action in the vertebrate central nervous system. In Handbook of Physiology, Section 1, Vol. 4, V. B. Mountcastle, and F. E. Bloom, eds., pp. 1-114, American Physiology Society, Bethesda, MD

Sikes, R. W., and B. A. Vogt (1987) Afferent connections of anterior thalamus in rats: Sources and association with muscarinic acetylcholine receptors. J. Comp. Neurol. 256: 538-551.

Sillito, A. M., J. A. Kemp, and N. Berardi (1983) The cholinergic influence on the function of the cat dorsal lateral geniculate nucleus Brain Res. 280: 299-307.

Singer, W. (1973) The effect of mesencephalic reticular stimulation on intracellular potentials of cat lateral geniculate nucleus. Brain Res. $61: 35-54$

Smith, Y., D. Paré, M. Deschênes, A. Parent, and M. Steriade (1988) Cholinergic and non-cholinergic projections from the upper brainstem core to the visual thalamus in the cat. Exp. Brain Res. 70: 166-180.

Somogyi, G., F. Hajdu, and T. Tömböl (1978) Ultrastructure of the anterior ventral and anterior medial nuclei of the cat thalamus. Exp. Brain Res. 31: 417-431.

Steriade, M., and L. L. Glenn (1982) Neocortical and caudate projections of intralaminar thalamic neurons and their synaptic excitation from midbrain reticular core. J. Neurophysiol. 48: 352-371.

Steriade, M., and J. A. Hobson (1976) Neuronal activity during the sleep-waking cycle. Prog. Neurobiol. 6: 155-376.

Steriade, M., and R. R. Llinás (1988) The functional states of the thalamus and the associated neuronal interplay. Physiol. Rev. 68 . 649-742.

Steriade, M., G. Oakson, and A. Diallo (1977) Reticular influences on lateralis posterior thalamic neurons. Brain Res. 131: 55-71.

Steriade, M., A. Parent, and J. Hada (1984) Thalamic projections of nucleus reticularis thalami of cat: A study using retrograde transport of horseradish peroxidase and fluorescent tracers. J. Comp. Neurol. 229: 531-547.

Steriade, M., A. Parent, D. Paré, and Y. Smith (1987) Cholinergic and non-cholinergic neurons of cat basal forebrain project to reticular and mediodorsal thalamic nuclei. Brain Res. 408: 372-376

Steriade, M., D. Paré, A. Parent, and Y. Smith (1988) Projections of cholinergic and non-cholinergic brainstem reticular neurons to relay and associational thalamic nuclei in the cat and macaque monkey. Neuroscience 25: 47-67.

Sutin, E. L., and D. M. Jacobowitz (1988) Immunocytochemical localization of peptides and other neurochemicals in the rat laterodorsal tegmental nucleus and adjacent area. J. Comp. Neurol. 270: 243-270.

Takeuchi, Y., G. V. Allen, and D. A. Hopkins (1985) Transnuclear transport and axon collateral projections of the mamillary nuclei in the rat. Brain Res. Bull. 14: 453-468.

Van Der Kooy, D., H. G. J. M. Kuypers, and C. E. Castman-Berrevoets (1978) Single mamillary cells with divergent axon collaterals. Demonstration by a simple fluorescent retrograde double labeling technique in the rat. Brain Res. 158: 189-196.

Velayos, J. L., J. Jimenez-Castellanos, and F. Reinoso-Suarez (1989) Topographical organization of the projections from the reticular thalamic nucleus to the intralaminar and medial thalamic nuclei in the cat. J. Comp. Neurol. 279: 457-469.

Vincent, S. R., K. Satoh, D. M. Armstrong, and H. C. Fibiger (1983) Substance $P$ in the ascending cholinergic system. Nature 306: 688691.

Wilson, P. D., J. P. Pecci-Saavedra, and R. W. Doty (1973) Mesencephalic control of lateral geniculate nucleus in primates. II. Effective loci. Exp. Brain Res. 18: 204-213.

Woody, C. D., B. E. Swartz, and E. Gruen (1978) Effects of acetylcholine and cyclic GMP on input resistance of cortical neurones in awake cats. Brain Res. 158: 373-395.

Woolf, N. J., and L. L. Butcher (1986) Cholinergic systems in the rat brain: III. Projections from the pontomesencephalic tegmentum to the thalamus, tectum, basal ganglia, and the basal forebrain. Brain Res. Bull. 16: 603-637. 